\title{
Mortality by socio-economic class and its impact on the retirement schemes: how to render the systems fairer?
}

\section{Anca Jijiie $^{1} \mathbb{D}$. Jennifer Alonso-García ${ }^{2,3} \cdot$ Séverine Arnold $^{1}$}

Received: 9 January 2020 / Revised: 16 March 2021 / Accepted: 19 August 2021 /

Published online: 25 November 2021

(C) The Author(s) 2021

\begin{abstract}
Many OECD countries have addressed the issue of increased longevity by mainly increasing the retirement age. However, this kind of reforms may lead to substantial transfers from those with shorter lifespans to those that will live longer than the average, as they do not necessarily take into account the socio-economic differences in mortality. The contribution of our paper is therefore twofold. Firstly, we illustrate how both a Defined Benefit and a Notional Defined Contribution pay-as-you-go scheme can put the lower social economic classes at a disadvantage, when compared to the actuarially fair pensions. In contrast to that, higher classes experience a gain. This is due to the fact that mortality rates per socio-economic class are not considered by either scheme. Consequently, we propose a model that determines the parameters for each scheme and class which would render the pensions fairer even when no socio-economic mortality differences are considered.
\end{abstract}

Keywords Retirement age $\cdot$ Pay-as-you-go $\cdot$ Public pensions $\cdot$ Adequacy $\cdot$ Fairness Class-specific parameters

Anca Jijiie

anca.stefania.jijiie@gmail.com

Jennifer Alonso-García

jennifer.alonso.garcia@ulb.be

Séverine Arnold

Severine.Arnold@unil.ch

1 Faculty of Business and Economics (HEC Lausanne), University of Lausanne, Lausanne, Switzerland

2 ARC Centre of Excellence in Population Ageing Research (CEPAR), UNSW, Sydney, Australia

3 Department of Mathematics, Faculty of Sciences, Université Libre de Bruxelles, Bruxelles, Belgium 


\section{Introduction}

In this paper, we address the issue of actuarial fairness of pension schemes, given that socio-economic differences in mortality do exist and their impact is non-negligible. Besides discussing this matter through an example, we aim at providing an easy-to-implement solution, allowing policy-makers to not only improve the actuarial fairness of their pension schemes, but also to assess the extent to which pensions should differ depending on the socio-economic class.

Increased longevity has been a well known and well documented phenomenon in recent years, with significant impact on pension schemes around the world. For example, Oeppen and Vaupel [33] note that the world life expectancy has roughly doubled in the course of 20 years, which has impacted the social needs of societies, among which pensions are included. OECD [30] estimates that on average, taking into account future mortality improvements leads to higher life expectancies for both men and women than when period life tables are used ( 2 years more for men and 2.5 years more for women at age 65, based on 2010 data). Hence the choice of mortality table becomes fundamental for pension funds and life insurance companies, with potential estimated shortfalls in reserves due to the use of period tables instead of generational ones going up to $20 \%$. Bisetti and Favero [6] project mortality for Italy and find that the longevity risk for the Italian pension system over the years could rise from $0.06 \%$ of the GDP in 2012 to $4.35 \%$ in 2050. Määttänen et al. [24] also discussed the impact of increased longevity on five European countries and conclude that the cost, which is estimated as positive, would have to be paid either by the currently retired or the future generation. Moreover, they remark that the Finnish earnings-related pension system is not yet completely capable to sustain the ageing population. Lastly, Kisser et al. [20] estimate, based on US panel data, that each additional year of life expectancy would increase the liabilities of US public and private pension funds by $3 \%$.

With many pension schemes forming the first pension pillar still financed on a pay-as-you-go basis (the contributions perceived during one period are used to pay benefits during that same period), the burden of the increased life expectancy is far from getting any lighter (as also pointed out by Stevens [42]). Indeed, in order to address this issue, many countries have proceeded to reforming their first pillars. OECD [31] notes that almost all OECD countries have taken steps towards changing their systems, the most common reform measure being the increase in the minimum or legal retirement age. However, we must point out that such a measure does not account for the heterogeneity in mortality induced by socioeconomic class. The relationship between socio-economic class and mortality has already been documented in the literature. For instance, Villegas and Haberman [46] find significant differences in mortality between the most deprived and the least deprived individuals in England. Similarly, Nelissen [28] finds 4.5 years of difference in life expectancy between individuals in the lowest social class and those in the higher social class, remarking that this impacts not only earnings, but also pension contributions and benefits. Shkolnikov et al. [39] look into socioeconomic mortality for German men, based on survey data and find that those 
belonging to a higher class, defined through occupation, can live more than two years longer than men in the lower class. Using a micro-level lifetime dataset from a Dutch pension fund, Van Berkum et al. [43] show that one of the most relevant risk factors explaining longevity gap between the participants within a fund is the salary, while Chetty et al. [14] find that, in the United States, life expectancy rises with the income. Olshansky et al. [34] also remark there is a difference in longevity in the US in function of the level of education, as well as race. On a similar note, Meara et al. [26] observe that the gains in life expectancy have not occurred evenly for all socio-economic groups, defined in the paper by level of education, with highly educated individuals having more important improvements in life expectancy. Consequently, as lower socio-economic classes have a lower life expectancy than the higher classes, with inequalities still expected to rise (as also remarked by Ayuso et al. [3]), increasing the retirement age would lead to individuals of lower classes spending even less time in retirement, as also pointed out by Sanzenbacher et al. [38]. Hence transfers are taking place towards those with a higher than average life expectancy, pointing out towards an unfair system, as also stated by Nelissen [28], Barnay [4] or Mazzaferro et al. [25]. A similar conclusion was also reached by Brown [12], who found that when annuities are the same for all individuals, redistributions appear from the less wealthy to those that are in a better financial state.

Moreover, we must note that, besides not considering the socio-economic differences in mortality when increasing the retirement age, pension schemes do not take into account such differences when calculating the benefits. In particular, our paper deals with two pay-as-you-go systems: a Defined Benefit (DB) and a Notional Defined Contribution (NDC) scheme. If in a DB scheme, the benefits are fixed based on the average salary and the contribution period of an individual, with the contribution rates deriving from the benefits ${ }^{1}$, in NDC schemes, each person has a notional account in which contributions are accumulated at a notional interest rate. At the retirement age, based on the mortality assumptions, the value accumulated into the accounts is transformed into a pension amount paid annually. Hence the benefits depend on the notional rate awarded, as well as on the mortality assumptions ${ }^{2}$. However, in practice, contribution rates are equal for all individuals in both DB and NDC systems, therefore not considering the socio-economic differences. Moreover, mortality by socio-economic class is not considered in determining the benefits under the NDC systems, which generally make use of unisex mortality tables. To illustrate this point, we use projected salaries and mortality by level of education ${ }^{3}$ to calculate and compare the DB or NDC pensions with the actuarially fair pensions (in other

\footnotetext{
1 DB schemes are widespread and countries such as Austria, France, Belgium, Spain, Japan and United States fall under this scheme [OCDE, [29]]. For a more detailed description of DB schemes, see Bodie et al. [7] or Wilcox [47].

2 NDCs have been first implemented in Italy in 1995 and have since been introduced in countries such as Latvia (1996), Poland (1999), Sweden (1999) and Norway (2011). For a more detailed description of the NDC system, see, for example, Palmer [35], Börsch-Supan [8], Vidal-Meliá et al. [45] or Arnold et al. [2] and for a recent overview of country-specific features, see Alonso-García and Devolder [1].

3 A list on the existing literature linking mortality to the level of education can be found in Ayuso et al. [3].
} 
words, what each individual should receive given their contributions and their classspecific mortality). Our numerical example shows that, under the parametrisation considered, neither one of the two schemes is fair. In fact, higher socio-economic classes seem to gain with respect to the actuarially fair pension, while lower classes would receive less than what is actuarially fair. A similar conclusion was reached by Caselli et al. [13] and Mazzaferro et al. [25]. In other words, at a given retirement age, there exists a gap between what the individual should receive in order to maintain actuarial fairness and what is actually received.

It is important to note here that one of the key objectives of social security pension schemes, is the redistribution of income from the more wealthy to those with lower incomes in order to ensure a subsistence level for all individuals, and thus, social security schemes do not and can not aim actuarial fairness. However, by not considering the socio-economic mortality differences in the calculation of the pension benefits, the schemes disadvantage those in lower socio-economic classes, defined here in terms of the level of education, while higher socio-economic classes are gaining with respect to the actuarially fair framework. Transfers go then in the reverse order than intended by social security schemes. Therefore, aiming at fairer pensions appears to be the first step in order to ensure the subsistence level for all individuals, as lower socio-economic classes will see their pension amount increasing, while higher classes will see it decreasing. Naturally, this might not be sufficient to guarantee the subsistence level to all, but it goes in the right direction. Therefore, the identified gap existing between what the individual should receive in order to maintain actuarial fairness and what is actually received, should and can be filled by adjusting the parameters of the pension schemes, as it will be shown in this paper.

Even if many studies have focused on the link between the retirement age and the socio-economic class, defined among others in function of the level of education, (see, for example, Sanzenbacher et al. [38], Munnell et al. [27], Rutledge et al. [37], Venti and Wise [44] or Stenberg and Westerlund [41]), not enough has been said on what could be done to improve the fairness of the systems when the retirement age is fixed. In particular, the following studies are closer linked to this idea and therefore to our paper. Belloni and Maccheroni [5] perform an analysis of the actuarial fairness of the Italian system, considering white- and blue-collar occupational differences and find that white-collar employees have a higher present value ratio ${ }^{4}$. Moreover, they remark that the Italian system is still unfair, even after the transition from the DB to the NDC scheme. However, the only suggested measure for improving the situation is the use of projected mortality, instead of the static mortality used by the Italian system, in the calculations of the NDC pension benefits. Bravo et al. [10] also note the importance of considering heterogeneity in mortality, based on socioeconomic factors, in the calculations of pension benefits, listing different possible

\footnotetext{
4 The present value ratio is defined as the ratio of the present value of benefits and the present value of contributions. It thus shows how much is returned to the worker for each monetary unit paid as contribution. A present value ratio of one indicates actuarial fairness. It is a concept previously used in the literature (for instance, see Belloni and Maccheroni [5]).
} 
interventions to mitigate its effect, including offering different accrual and accumulation rates to each socio-economic group, without going into more technical details on these two possibilities. Holzmann et al. [17] define actuarial fairness in terms of a tax/subsidy rate for the NDC system and suggest different ways to introduce contribution rates dependent on the life expectancy of each socio-economic group. Lastly, though not specifically aiming at improving the fairness of the pension systems, Kuivalainen et al. [22] note that socio-economic differences surpass gender differences, in terms of pension income in Finland, while Kudrna et al. [21] propose introducing a means-tested pension in order to tip the scale towards those belonging to lower socio-economic classes.

Our paper contributes to the existing literature by offering, for the first time to the best of our knowledge, a tractable method that allows the systems to achieve greater actuarial fairness at a given retirement age, when the socio-economic differences in mortality are not considered by the pension schemes. This is done by adjusting the system parameters, namely the interest rate, accrual rate and notional rate, by socioeconomic class, in order to compensate for the use of general mortality in the benefit calculations. The previously mentioned gap between the fair pension and the actual benefit is thus filled. Additionally to illustrating how such a process would occur based on our data by level of education, we aim at providing straightforward formulas for defining these parameters according to the socio-economic class and to the amount of data on socio-economic mortality rates available. Approximations to this formulas are also provided, in order to offer policy-makers an intuitive framework serving a double purpose. Determining such class-specific parameters will firstly allow those making decisions with respect to the pension systems to understand the importance of socio-economic mortality, by easily quantifying the extent to which pensions should differ across socio-economic class in a fairer system. Furthermore, our framework can be implemented in practice, allowing for fairer pensions even when class-specific mortality rates are not considered by the pension schemes.

The remainder of this paper is structured as follows: we define the DB and NDC pensions in Sect. 2. In Sect. 3, we assess the actuarial fairness of the DB and NDC schemes, based on our data by level of education and a defined set of parameters. We consequently illustrate, in the same section, the steps to take in order to adjust the parameters by class, along with the resulting values based on our data. We generalise our framework by providing mathematical expressions for the class-specific rates, dependant on the detail of the available data in Sect. 4. Lastly, we provide further avenues for our analysis in Sect. 5 and summarise our conclusions in Sect. 6.

\section{The pension schemes}

In this paper, we consider two pension schemes commonly used in practice, namely a Defined Benefit (DB) and a Notional Defined Contribution (NDC) scheme. Since we are interested in the social security systems (in other words, the first pillar in the three pillar pension system proposed by the World Bank [48]), these pension 
schemes have a pay-as-you-go (PAYG) financing ${ }^{5}$. The pensions, defined hereafter, though considering the salaries per socio-economic class, do not take into account the mortality by social class. Hence, the relationship between contribution paid and benefits received might not correspond to the definition of an actuarially fair scheme. Indeed, in order to be actuarially fair, a pension scheme has to ensure, by definition, a present value ratio of one, so in other words that the present value at the moment of entry into the system of all contributions paid equals the present value at the same moment in time of all future benefits received, given salaries and mortality levels by socio-economic class, to account for heterogeneity. We refer to the pension satisfying this requirement as the theoretical pension. ${ }^{6}$ Although PAYG systems do not strive for actuarial fairness, a sustainable PAYG scheme will also be fair if the actuarial fairness is evaluated using an interest rate that is equal to the growth rate of the wage bill. Hence, the theoretical pension defined as specified above corresponds to the amount that ensures both the sustainability of the scheme and its fairness, but only if the interest rate is given by the growth rate of the wage bill. Consequently, utilising a different interest rate does not fulfil the above mentioned requirements for the PAYG systems and would thus not aid in establishing the fairness of the schemes as defined in this paper, since the sustainability of the systems cannot be guaranteed. Therefore, in order to asses the fairness of the DB and NDC schemes, we will need to compare the pensions given by each type of scheme to the theoretical pension.

As previously stated, the remainder of this section is dedicated to defining the DB and NDC pensions. For this, we allow $Z$ socio-economic classes to coexist in the system. Individuals belong to the same class from the age of entry into the system, namely $x_{0}^{i}$, where $i$ designates the class, until death. Retirement is taken at age $x_{r}^{i}$ and the maximum lifespan is $\omega$. Moreover, there is no unemployment or disability ${ }^{7}$. During their working years, individuals pay contributions as a percentage $\pi$ of their salaries. To ease notation, the gender is not indicated in the given formulas through an index. However, the formulas are valid for both men and women and the subsequent analysis is split by both gender and socio-economic class.

\subsection{The Defined Benefit (DB) scheme}

For the Defined Benefit (DB) scheme, we define the retirement benefit for an individual of socio-economic class $i$, retiring at age $x_{r}^{i}$ at time $t$ as $P_{x_{r}^{i}, t}^{i, D B}$ in Eq. (1). Commonly, public DB pension schemes take into account the average wage over the last $n$ working years, which we denote as $\bar{W}_{t}^{i}$. The pension is also a function of the

\footnotetext{
5 Though some countries have pre-funded first pillars, we focus here only on PAYG systems.

${ }^{6}$ Note here that we assume that only salaries contribute to pensions. Naturally, other revenues could contribute to pensions, such as income taxes or VAT, and hence the proposed modeling framework would need to be adapted. However, such analysis needs to be country-specific as each country may have very different systems.

${ }^{7}$ Including unemployment and disability in our model would not change the conclusions of this paper. Considering these two aspects will reduce the career length and thus reduce pensions, but it will not affect the gap between the fair pension and the actual benefit that has to be filled in order to achieve greater actuarial fairness.
} 
accrual rate per year of affiliation, $A R^{i}$. In order to keep our formulas as general as possible, we consider that the accrual rate differs across the socio-economic classes. Moreover, if the individuals retire early, so before the legal retirement age $x_{\text {legal }}$ (hence $x_{r}^{i}<x_{\text {legal }}$ ), a penalty of $b_{x_{r}^{i}} \%$ is applied. Similarly, if retirement is postponed $\left(x_{r}^{i}>x_{\text {legal }}\right)$, a bonus of $b_{x_{r}^{i}} \%$ is awarded. We also note that the coefficients of penalty and bonus are dependent on the age at which the retirement is taken, but not on the class. In other words, postponing retirement for one year implies a different bonus percentage than postponing it for two years. These factors should be calculated actuarially, such that the equivalence between the present value of contributions and that of benefits is ensured. Finally, we note that for the purpose of this paper, the DB pension is described as a function of the accrual rate $A R^{i}$.

$$
P_{x_{r}^{i}, t}^{i, D B}\left(A R^{i}\right)= \begin{cases}\bar{W}_{t}^{i} \cdot A R^{i} \cdot\left(x_{r}^{i}-x_{0}^{i}\right)\left(1-b_{x_{r}^{i}} \%\right), & \text { if } x_{r}^{i}<x_{\text {legal }} \\ \bar{W}_{t}^{i} \cdot A R^{i} \cdot\left(x_{r}^{i}-x_{0}^{i}\right), & \text { if } x_{r}^{i}=x_{\text {legal }} \\ \bar{W}_{t}^{i} \cdot A R^{i} \cdot\left(x_{r}^{i}-x_{0}^{i}\right)\left(1+b_{x_{r}^{i}} \%\right), & \text { if } x_{r}^{i}>x_{\text {legal }}\end{cases}
$$

Moreover, $\bar{W}_{t}^{i}$ is given by Eq. (2) below, where $W_{x, t+x-x_{r}^{i}}^{i}$ is the salary of a person of age $x$ at time $t+x-x_{r}^{i}$, belonging to class $i$, given that the retirement age $x_{r}^{i}$ is reached at time $t^{8}$.

$$
\bar{W}_{t}^{i}=\frac{1}{n} \sum_{x=x_{r}^{i}-n}^{x_{r}^{i}-1} W_{x, t+x-x_{r}^{i}}^{i}
$$

Though the contribution rate in the DB scheme should ensue from the level of the pension and the mortality assumptions, that is not the case in typical social security systems. In practice, a constant contribution across time and social classes is used. This is why we adopt the same condition for the contribution rate. Hence $\pi$ is a fixed percentage for all classes and genders, as well as across time and age. Nevertheless, Sect. 5.3 discusses the case when the contribution rate is different for each socioeconomic class.

\subsection{The Notional Defined Contribution (NDC) scheme}

As pointed out by the World Bank [49], the Notional Defined Contribution scheme mimics the mechanisms of a classical (funded) Defined Contribution scheme. If in a Defined Contribution scheme, each person has an individual account in which contributions are accumulated at a given interest rate, the process is similar in the NDC scheme. A notional account is created for every member in which contributions are

\footnotetext{
${ }^{8}$ We do not consider capped salary in the DB formula as we only use the average salary for each socioeconomic class (see Sect. 3). Therefore, very high salaries that would be capped to determine the pension amount but not the contributions, are not directly included in our model. Naturally, a nice extension of the model would be to include such feature, once data on salary distribution are available for each socioeconomic group.
} 
accumulated at a notional rate $n r^{i}$ (once again, for generalisation purposes, we allow the notional rate to depend on the class). However, these accounts, as well as the accumulation, are only virtual, since we are still in a PAYG setting. Moreover, the notional interest rate is based on a macroeconomic index that will ensure the sustainability of the system, such as the growth rate of GDP. It is not, therefore, an actual return on the financial market. In a NDC scheme, at the time of retirement, the present value of future pensions of a specific cohort should be, by definition, equal to the accumulated value of that cohort's savings account ${ }^{9}$. The pension amount is thus given by Eq. (3) below, where $L_{x, t}^{u n i s e x}$ is the number of people of age $x$ alive at time $t$ (given unisex mortality rates). In this case, the pension is calculated using unisex mortality, thus there is no difference made between classes or genders. Lastly, similarly to the $\mathrm{DB}$ pension, to ease the comprehension of the remainder of this paper, the NDC pension is defined as a function of the notional rate.

$$
P_{x_{r}^{i}, t}^{i, N D C}\left(n r^{i}\right)=\frac{\pi \cdot \sum_{x=x_{0}^{i}}^{x_{r}^{i}-1} L_{x, t-x_{r}^{i}+x}^{\text {unisex }} \cdot W_{x, t-x_{r}^{i}+x}^{i} \cdot\left(1+n r^{i}\right)^{x_{r}^{i}-x}}{\ddot{a}_{x_{r}^{i}, t}^{\text {unisex }, \beta}\left(n r^{i}\right) \cdot L_{x_{r}^{i}, t}^{\text {unisex }}}
$$

Equation (4) provides the general definition for an annuity factor $\ddot{a}_{x_{r}, t}^{i, \beta}(r)$ as a function of a given interest rate $r$, thus following Bowers et al. [9]. Once again, $i$ designates the class, while $\beta$ is the indexation rate. Furthermore, $p_{x, t}^{i}$ is the class-specific survival rate, while ${ }_{k} p_{x, t}^{i}$ is the probability that a person of age $x$ at time $t$ survives another $k$ years. Hence, $\ddot{a}_{x_{r}^{i}, t}^{\text {unisex, } \beta}\left(n r^{i}\right)$, used in Eq. (3), follows the same definition, but uses the unisex mortality and the notional rate $n r^{i}$ instead.

$$
\ddot{a}_{x_{r}, t}^{i, \beta}(r)=\sum_{k=0}^{\omega-x_{r}}\left(\frac{1+\beta}{1+r}\right)^{k} \cdot{ }_{k} p_{x_{r}, t}^{i}
$$

\section{Assessing and improving the fairness of the pension schemes: a numerical example}

In this section, we asses the fairness of both a DB and a NDC scheme for a given set of parameters. Subsequently, we optimise the parameters of each scheme in order to improve their fairness. As stated, this is a numerical example meant to illustrate how the actuarial fairness of a pension scheme can be improved in order to account for the mortality differences between socio-economic classes, given a set of original parameters, such as the contribution rates and the legal retirement age, among others.

\footnotetext{
9 We define here the NDC scheme such that the survival dividends (also referred to as inheritance gains) are distributed to the living individuals in the cohort at the time of retirement. For a detailed analysis of NDC schemes, please see Vidal-Meliá et al. [45] and Arnold et al. [2].
} 


\subsection{The French data}

A first natural step in our example is, of course, assessing the fairness of a DB and a NDC pension scheme, when socio-economic differences are considered. For this, we use the data in function of the degree of education ${ }^{10}$ provided by the French Office of Statistics. Table 1 summarises the categories for this classification, to which we attribute a category label. Hence D1 refers to the class with the highest level of education, namely people having an university degree, while D5 represents the class with no formal education. The French Office of Statistics ${ }^{11}$ offers historical data on both salaries and mortality for these classes, which we use to project values for these two variables for the period 2016-2116 ${ }^{12}$. The details regarding the data and the projections for salaries can be found in Section A, while Section B contains the details regarding the mortality data and projections. This classification suits our purpose, given that both salaries and mortality are provided for the same classes. In addition, the historical data regarding the class-specific mortality allows us to project the mortality rates per class used for the remainder of this example.

Moreover, we define in the same table, the entry ages $x_{0}^{i}$ for each class. Individuals with a higher level of education will enter the labour market later than the ones with lower degrees. Hence, people in category D5 enter as early as 15, while those with an university diploma will enter much later, at age 21 . The entry age for the lowest class corresponds to the first age for which data is available, given the assumption that people with no formal education will start working at the earliest time possible. For the rest of the classes, we generally follow the description of the French educational system provided by Hörner et al. [18]. They note that the certificates for professional competence and studies are awarded at age 17, while those doing the Baccalaureate exam finish at 18. Once the school studies are completed, a Bachelor diploma requires another three years of studies, hence the entry age of 21 for the class D1. The only deviation from this description that we allow here is related to those having a National Diploma. Though Hörner et al. [18] place the age of obtaining this diploma at 15 , we decided to put it to 16 to allow a difference between the class D4 and D5.

\subsection{Assessing the fairness of the pension schemes}

As already indicated in the first paragraph of Sect. 2, the two pension schemes described in Sects. 2.1 and 2.2 do not necessarily ensure actuarial fairness. In

\footnotetext{
${ }_{10}$ Defining socio-economic class in terms of the level of education limits the potential transitions between classes, as well as the incentives to switch class closer to the retirement age, since a higher level of education requires additional years of study. Therefore this classification allows us to make the assumption, for simplification purposes, that individuals remain in the same class throughout the years.

11 https://www.insee.fr/en/accueil.

12 Although forecasting values on such a long period is not desirable, as it raises questions on the reliability of the values, it was in this case a necessary exercise. Because we require the salaries over the entire career of the individuals, together with their mortality for the entire lifespan, the long forecasting period was unavoidable.
} 
fact, the differences in life expectancy across socio-economic groups affect the actuarial fairness of the system, that is, the relationship between the contributions paid and the retirement benefits received. By definition, under an actuarially fair scheme, the present value at the moment of entry into the system of all contributions paid should equal the present value at the same moment of all future benefits received. Hence, we denote by $P_{x_{r}^{i}, t}^{i, t h}$, defined in Eq. (5), the theoretical pension, that is the amount implied by an actuarially fair system for an individual from socio-economic class $i$ and retiring at age $x_{r}^{i}$ at time $t$. As before, $W_{x, t}^{i}$ is the salary of a person of age $x$ at time $t$, belonging to class $i$, while $r$ is the interest rate. Furthermore, ${ }_{x-x_{0}^{i}} p_{x_{0}^{i}, t-x_{r}^{i}+x_{0}^{i}}$ is the probability of an individual from class $i$, aged $x_{0}^{i}$ at time $t-x_{r}^{i}+x_{0}^{i}$ (the time of entry in the system, where $t$ corresponds to the time when retirement occurs) to survive to age $x$. As stated before, the interest rate $r$ used here, should correspond to the growth rate of the wage bill (so $1+r=(1+g)(1+d)$, with $g$ the growth rate of salaries and $d$ the growth rate of the population).

$$
P_{x_{r}^{i}, t}^{i, t h}(r)=\frac{\pi \cdot \sum_{x=x_{0}^{i}}^{x_{r}^{i}-1} W_{x, t-x_{r}^{i}+x}^{i} \cdot(1+r)^{-\left(x-x_{0}^{i}\right)}{ }_{x-x_{0}^{i}} p_{x_{0}^{i}, t-x_{r}^{i}+x_{0}^{i}}^{i}}{\ddot{a}_{x_{r}^{i}, t}^{i, \beta}(r) \cdot x_{x_{r}^{i}-x_{0}^{i}} p_{x_{0}^{i}, t-x_{r}^{i}+x_{0}^{i}}^{i} \cdot(1+r)^{-\left(x_{r}^{i}-x_{0}^{i}\right)}}
$$

Please note that the pension $P_{x_{r}^{i}, t}^{i, t h}$ does not depend on the pension scheme studied, but that it solely depends on the life expectancy of the individual, their wages and the assumptions with regards to the interest rate $r$ and contribution rate $\pi$. In practice, the pension actually paid will depend on the design of the public pension scheme. We can therefore compare the theoretical pension $P_{x_{r}^{i}, t}^{i, t h}(r)$ to the one paid under the two different pension schemes considered here, namely the DB and the NDC scheme.

Consequently, in order to determine the fairness of each of the scheme, for each class, we use Eq. (6) below, in which the difference in pension capitals at time $t$ is denoted by $P V_{x_{r e f}, t}^{i, u}\left(x_{r}^{i}\right)$. In the previously mentioned equation, we compare the pension capital associated with a fair pension $\left(P_{x_{r}^{i}, t+x_{r}^{i}-x_{r e f}}^{i, t h}\right)$ and the pension capital based on the (actual) amount received $\left(P_{x_{r}^{i}, t+x_{r}^{i}-x_{r e f}}^{i, u}\right.$, with $\mathrm{u}=\{\mathrm{DB}, \mathrm{NDC}\}$ and $i$ the class). The pension capital is calculated as the present value, at the fixed age $x_{r e f}$, of future pension payments, given the retirement age $x_{r}^{i} \geq x_{r e f}$ reached at time $t+x_{r}^{i}-x_{r e f}$. Furthermore, as before, $r$ is the interest rate and ${ }_{x_{r}^{i}-x_{r e f}} p_{x_{r e f}, t}^{i}$ the class-specific probability that a person of age $x_{r e f}$ at time $t$ survives until age $x_{r}^{i}$. The annuity factor $\ddot{a}_{x_{r}^{i}, t}^{i, \beta}(r)$ is given by Eq. (4). Consequently, a value of $P V_{x_{r e f}, t}^{i, u},\left(x_{r}^{i}\right)$ equal to zero means the pension received is actuarially fair, while a positive value indicates that the pension is more than fair and thus, the individuals are gaining. Conversely, a negative value means the pension is less than fair and the individuals incur losses. 
Table 1 Socio-economic categories by level of education (France) and their entry ages into the system, adapted from Hörner et al. [18]

\begin{tabular}{llr}
\hline Category & Descriptive & $x_{0}^{i}$ \\
\hline D1 & Superior to Baccalaureate & 21 \\
D2 & Baccalaureate & 18 \\
D3 & CPC (Certificate of professional competence), CPS (Certificate of & 17 \\
& professional studies) & 16 \\
D4 & National Diploma, CPrS (Certificate of primary studies) & 15 \\
D5 & No diploma & \\
\hline
\end{tabular}

$$
\begin{aligned}
P V_{x_{r e f}, t}^{i, u}\left(x_{r}^{i}\right)= & \left(P_{x_{r}^{i}, t+x_{r}^{i}-x_{r e f}}^{i, u}-P_{x_{r}^{i}, t+x_{r}^{i}-x_{r e f}}^{i, t h}\right) \cdot(1+r)^{-\left(x_{r}^{i}-x_{r e f}\right)} \\
& x_{x_{r}^{i}-x_{r e f}} p_{x_{r e f}^{i}, t}^{i} \cdot \ddot{a}_{x_{r}^{i,}, t+x_{r}^{i}-x_{r e f}}^{i, r)}
\end{aligned}
$$

In order to proceed with our numerical illustration, we start by fixing the contribution rate $\pi=14.3 \%$. This rate ensures the equality between the present value of the contributions and the present value of DB benefits (as defined in Sect. 2.1) for an average individual that enters the market at age $x_{0}=17$, retires at the legal retirement age, faces unisex mortality and has average earnings (hence no class distinction is made), given an accrual rate $A R$ of $1 \%$. An interest rate $r=1.8 \%^{13}$ is used to determine the theoretical pensions for each class, as well as the value of the annuity in Eq. (6).

For simplification purposes, the indexation rate $\beta$ is set to zero ${ }^{14}$. Hereafter, we assess, in turns, the actuarial fairness of a DB and a NDC scheme, for retirement ages going from 50 to 75 . Therefore, the reference age $x_{r e f}$ is the minimum retirement age considered here, namely 50 .

\subsubsection{The Defined Benefit scheme}

Assessing the fairness of the DB scheme described in Sect. 2.1, process done according to Eq. (6), starts by setting the legal retirement age $x_{\text {legal }}$ to 65 for both men and women, for all classes, value that aligns with the policy of many OECD countries (see OECD [32]). The accrual rate chosen is $A R=1 \%$, which is applied

\footnotetext{
${ }^{13}$ The variable $r$ is the interest rate used to assess the actuarial fairness of the system. It does not correspond to an interest rate traded on the financial market, but to the growth rate of the wage bill. For our illustration, the interest rate has a value of $1.8 \%$, which satisfies the relationship $1+r=(1+g)(1+d)$, with $g=1.4 \%$ the growth rate of salaries calculated from our data and $d=0.4 \%$ the growth rate of the population for the year 2016 in France.

${ }^{14}$ The indexation rate does not impact the results pertinent to the NDC scheme, since it impacts both types of pensions (NDC and theoretical) in the same way. However, a positive indexation rate would shift the values related to the DB schemes, meaning that the PV values calculated according to Eq. (6) increase with the indexation rate for all classes in the DB scheme.

${ }^{15}$ This rate implies that the individuals receive, depending on their class, between 44 and $50 \%$ of the average salaries over their entire careers. According to OECD [32], among the countries offering this accrual rate (1\%) we can find Hungary and Korea.
} 
to the average salary $\bar{W}$ calculated over the entire career for all the socio-economic classes. The bonus and penalty values $b_{x_{r}}$ are, just as for the contribution rate, calculated based on the average individual in the system, entering at age $x_{0}=17$, given an interest rate $r=1.8 \%$. They are therefore actuarially fair for the average individual, but not for each socio-economic class. The determined values ensure the equivalence between the present value of contributions and that of benefits and are given in Table 2. Hence, for example, if an individual retires at age 50, a penalty of $35.6002 \%$ is applied, while postponing the retirement to age 75 implies a bonus of $53.8640 \%$. Since the legal retirement age is set to 65 , there is no coefficient applied to this age. Given that these values are calculated based on an average person's experience, they are applied without distinction to all classes considered here and to both genders, as it is also done in practice. We calculate the value of $P V$, as given by Eq. (6), for retirement ages $x_{r}^{i}$ between 50 and 75. The results are displayed in Fig. 1, which shows the difference in pension capitals, discounted to age $x_{r e f}=50$, given a retirement age between 50 and 75 .

The results displayed in Fig. 1 allow us to observe that such a DB scheme as the one set up here favours greatly individuals with a higher education, while the lower classes either suffer losses or do not gain as much. Though the advantage is more striking for highly educated men than for women of the same class, namely D1, the observation holds for both genders ${ }^{16}$. For men in class D1, postponing the retirement time translates into a higher gain with respect to the theoretical pension. In other words, the DB pension increases quicker than the theoretical pension, making it more attractive to retire late. Moreover, we notice that the penalty coefficients are insufficient for this class, since even when retirement is taken at age 50, thus 15 years before the legal retirement age, the difference in pension capitals is still positive. However, for men of lower education the situation is almost inverted. If class D2 is close to a zero difference for the interval proposed here, we note that for the remaining classes the DB pension is always smaller than the actuarially fair pension. The losses increase the more retirement is postponed, noting that these categories are at a disadvantage. The bonus of retiring later than the legal age is not enough to catch up with the increase in the theoretical pension due to the accumulation of the contributions paid and the fewer years spent in retirement. Hence those living longer are favoured by the lack of mortality consideration. The same can be said in the case of women, since we observe right from the start that all classes gain with respect to the theoretical pension. For them, the DB pension is much more generous than the actuarially fair (or theoretical) framework, even at the minimum retirement age considered. What is more, postponing the retirement age increases the gain, meaning that the increase in the DB pension surpasses the increase in the theoretical pension. Lastly, we remark that the reason for which women always gain with respect to the theoretical pension lies also in the

\footnotetext{
16 In some countries where the first pillar is $\mathrm{DB}$, a cap is used with respect to the salaries insured under the system. However, because we make use of average salaries for this numerical example, we did not consider that a limit to the insured salaries was necessary. Nevertheless, in general, capping the salaries, and thus the DB pensions, would reduce the differences between high and low wage earners.
} 
calculation of the contribution rate, which uses unisex mortality. Due to the fact that female mortality is lower than the unisex one, the contribution rate is lower than it should be for women, leading to lower theoretical pensions. Hence the difference in pension capitals remains positive, with the DB pension being more generous than the theoretical framework.

\subsubsection{The Notional Defined Contribution scheme}

To study the fairness of the NDC scheme, described in Sect. 2.2, we keep the above mentioned contribution rate $\pi=14.3 \%$, the interest rate $r=1.8 \%$ and the indexation rate $\beta=0 \%$. We also set the notional rate of return, which we keep constant throughout time and across classes, to $1.8 \%$. This notional rate satisfies the same relationship as the interest rate $r$, namely $1+n r=(1+g)(1+d)$, with $g=1.4 \%$ the growth rate of salaries calculated from our data and $d=0.4 \%$ the growth rate of the population for the year 2016 in France. In Fig. 2 we see, as for the DB scheme, that women gain with respect to the theoretical pension and this gain increases the more the retirement is postponed. This is, in fact, not surprising, since the NDC pension is calculated based on the unisex mortality, while the theoretical pension uses the corresponding class-specific female mortality, which is lower than the unisex one. However, for men the situation is reversed, with all the categories losing with respect to the actuarially fair framework. Thus, for men, the notional interest rate used to accumulate the retirement capital is not enough to compensate for the increased longevity inferred by the use of the unisex mortality, compared to the class-specific one. Even more, the difference in pension capitals decreases the more the retirement is postponed, suggesting that the cost of one year of life less spent in retirement is higher in the NDC scheme than in the actuarially fair framework. This is of more consequence to men in class D5, for whom postponing retirement to higher ages implies a higher loss than for the other classes. Lastly, it is important to note that those with the highest level of education are better off than those in the other classes. Indeed, men in class D1 lose the least (though the difference with respect to class D2 is minimal), while women in the same class gain the most, when compared to the theoretical framework.

\subsection{Improving the fairness of the pension schemes}

As discussed above, for a given set of parameters, we find that neither the DB, nor the NDC scheme is fair, benefiting more the upper socio-economic classes and disadvantaging the lower classes. This is not the purpose of a social security system, which is meant to help those who really need it, namely the lower socioeconomic classes. Hence, the mortality by socio-economic class should be considered in the design of the different schemes, as well as in the calculation of the actuarially fair pensions. However, in practice, the mortality rates by social class are not often used or even known. In order to improve the fairness of the system and thus compensate for the lack of use of the class-specific mortality rates, we 
Table 2 Penalty and Bonus values for the DB scheme for $x_{\text {legal }}=65$

\begin{tabular}{llllllll}
\hline$x_{r}$ & $b_{x_{r}}(\%)$ & $x_{r}$ & $b_{x_{r}}(\%)$ & $x_{r}$ & $b_{x_{r}}(\%)$ & $x_{r}$ & $b_{x_{r}}(\%)$ \\
\hline 50 & 35.6002 & 57 & 22.4463 & 64 & 3.3061 & 71 & 27.0346 \\
51 & 33.9804 & 58 & 20.1572 & 65 & - & 72 & 32.8732 \\
52 & 32.2841 & 59 & 17.7405 & 66 & 3.8679 & 73 & 39.2397 \\
53 & 30.5059 & 60 & 15.1850 & 67 & 7.8401 & 74 & 46.2077 \\
54 & 28.6398 & 61 & 12.4785 & 68 & 12.1065 & 75 & 53.8640 \\
55 & 26.6794 & 62 & 9.6072 & 69 & 16.7008 & & \\
56 & 24.6174 & 63 & 6.5556 & 70 & 21.6617 & & \\
\hline
\end{tabular}
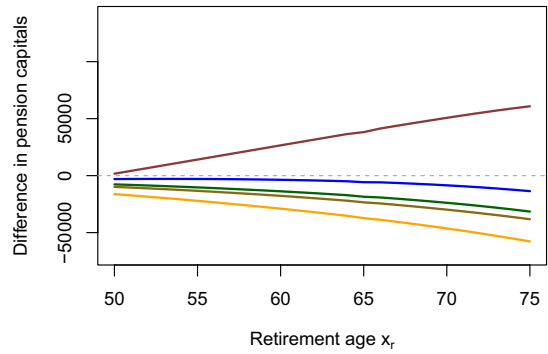

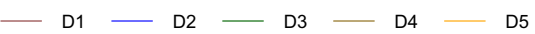

(a) $P V_{x_{r e f}, t}^{i, D B}\left(x_{r}\right)$ for men
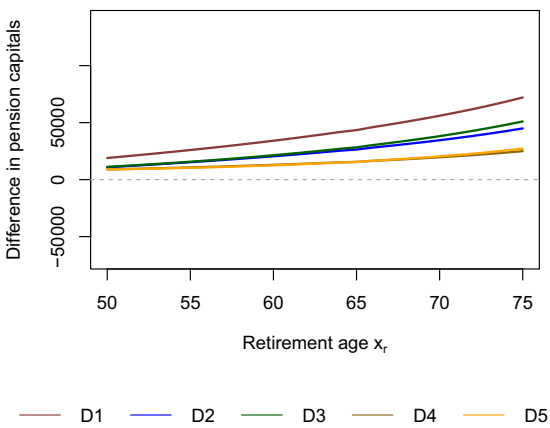

(b) $P V_{x_{r e f}, t}^{i, D B}\left(x_{r}\right)$ for women

Fig. 1 Difference between the DB pension capital and the theoretical pension capital, for individuals entering the system in 2016

suggest adapting the parameters that drive the pensions, namely the interest rate for the theoretical pensions, the accrual rate for the DB pensions and the notional rate for the NDC pension. Therefore, our process is done in steps, starting with the theoretical pension and so, with the interest rate, followed by the accrual rate and the notional rate for the DB and NDC schemes respectively. When socioeconomic mortality differences are not considered in the calculations of actuarially fair (or theoretical) pensions, the interest rate awarded to each class should be adapted to ensure that the fair pension remains at the same level, regardless of the use of class-specific survival rates. Formally, we search for the $r^{i}$, so the interest rate for each class $i$ that solves Eq. (7).

$$
P_{x_{r}^{i}, t}^{t h}\left(r^{i}\right)-P_{x_{r}^{i}, t}^{i, t h}\left(r^{\text {fixed }}\right)=0
$$

In other words, we fix the interest rate $r^{\text {fixed }}$ and calculate the theoretical pensions when the class-specific mortality rates are used. Hence $P_{x_{r}^{i}, t}^{i, t h}\left(r^{f i x e d}\right)$ is known for each class and gender. Consequently we look for the interest rate for each class that solves our equation, given that $P_{x_{r}^{i}, t}^{\text {th }}\left(r^{i}\right)$ utilises general mortality (so no class difference) 


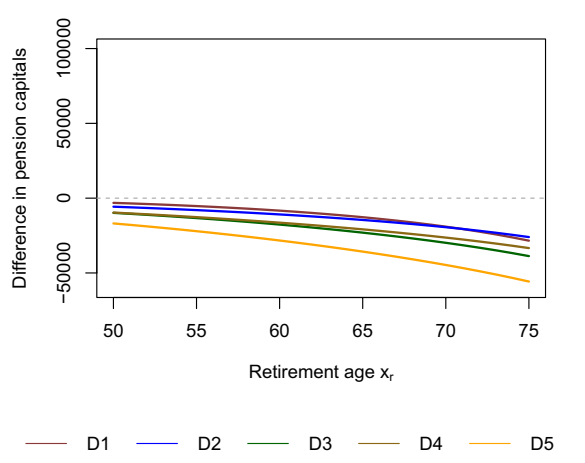

(a) $P V_{x_{r e f}, t}^{i, N D C}\left(x_{r}\right)$ for men

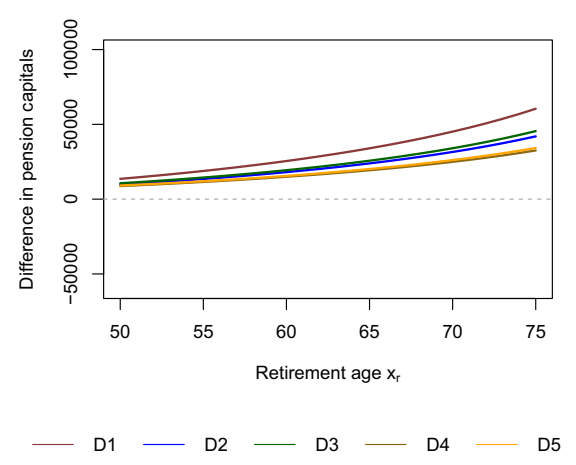

(b) $P V_{x_{r e f}, t}^{i, N D C}\left(x_{r}\right)$ for women

Fig. 2 Difference between the NDC pension capital and the theoretical pension capital, for individuals entering the system in 2016

rates ${ }^{17}$. Taking into account our numerical illustration provided until now, we set $r^{\text {fixed }}$ to $1.8 \%$, while the contribution rate remains $\pi=14.3 \%$. The entry ages into the system are those given in Table 1, while the retirement age is fixed at 65 for all classes and both genders, so $x_{r}^{i}=65, \forall i$. The resulting interest rates for individuals retiring in 2066 are displayed in Table 3. Consequently, those belonging to class D1 reaching the age of 65 in 2066 have entered the system in 2022, while those from classes D2 to D5 have entered in 2019, 2018, 2017 and 2016 respectively.

We note that the class-specific interest rates given in Table 3 are unique solutions to Eq. (7). Hence, the level of the interest rate for each class is not influenced by the type of system adopted, but is dependent on the value of $r^{\text {fixed }}$. Given our projections for the salaries and mortality for each class, we find that, in general the interest rates offered to lower social classes should be higher than those awarded to those with a higher education. This holds for both men and women, though the differences are slightly larger for men. Therefore, for individuals with a higher education and thus with higher survival probabilities, the use of the general mortality instead of the class specific one implies lower interest rates. If men belonging to class D1 only need an interest rate of $1.547 \%$, we would have to offer a rate of $1.9487 \%$ to those of class D5. Similarly, women of class D1 require an interest rate of $1.7585 \%$, while for class D5 a value of $1.8214 \%$ is found. This is normal, since for lower classes, the general mortality is lower than the classspecific one, inferring lower pensions if the $1.8 \%$ interest rate would have been used. Hence, to ensure the equality a higher interest rate should be awarded. The inverse holds for higher classes. Finally, it is important to note that, in general, the gap between the rates given to the classes is smaller for women due their

\footnotetext{
17 Though many alternatives exists for finding the root of our equation, we make use of the uniroot function in R, which is based on the bisection procedure (see https://stat.ethz.ch/R-manual/R-patched/library/ stats/html/uniroot.html).
} 
Table 3 Class-specific parameters for individuals retiring at age 65 in 2066, in percentages, as obtained from Eqs. (7), (8) and (9)

\begin{tabular}{llllllll}
\hline & \multicolumn{2}{c}{ Male } & \multicolumn{5}{l}{ Female } \\
\cline { 2 - 3 } Class & $r^{i}$ & $A R^{i}$ & $n r^{i}$ & & $r^{i}$ & $A R^{i}$ & $n r^{i}$ \\
\hline D1 & 1.5470 & 0.9070 & 1.9033 & & 1.7585 & 0.8443 & 1.4198 \\
D2 & 1.6620 & 1.0206 & 1.9724 & & 1.7671 & 0.8649 & 1.4405 \\
D3 & 1.7592 & 1.0756 & 2.0586 & & 1.7803 & 0.8703 & 1.4554 \\
D4 & 1.8111 & 1.1366 & 2.0958 & & 1.7872 & 0.9028 & 1.4759 \\
D5 & 1.9487 & 1.1872 & 2.2319 & & 1.8214 & 0.9171 & 1.5127 \\
\hline
\end{tabular}

closer mortality and salary profiles, observation that is also visible in Figs. 1b and $2 b$.

After determining the class-specific interest rates, we search for the accrual rate and the notional rate that would render the DB and the NDC pension, respectively, actuarially fair. In other words, we look for the rates that ensure the equality between the two types of pensions and the theoretical pension, respectively. Formally, this is given in Eqs. (8) and (9) below.

$$
\begin{aligned}
& P_{x_{r}^{i}, t}^{i, D B}\left(A R^{i}\right)=P_{x_{r}^{i}, t}^{t h}\left(r^{i}\right) \\
& P_{x_{r}^{i}, t}^{i, N D C}\left(n r^{i}\right)=P_{x_{r}^{i}, t}^{t h}\left(r^{i}\right)
\end{aligned}
$$

The solutions to these two equations are given in Table 3, alongside the values for the class-specific interest rates. We observe a similar situation for the accrual and notional rate for each class as for the interest rates. Both rates are higher for individuals with a lower education and hence lower salaries. We find that individuals with an university degree require an accrual rate of $0.907 \%$ in the case of men, while for women this value is $0.8443 \%$. On the other hand, for those with no formal education, the accrual rate is $1.1872 \%$ for men and $0.9028 \%$ for women. We notice then that the spread between the lowest and highest class is more important for men than for women. Hence, as before, the differences are more visible for men than for women. The situation is not much different when we look at the notional rate. The highest socio-economic class should receive a notional rate of $1.9033 \%$, in the case of men and $1.4198 \%$ in the case of women, while the lowest class is awarded a rate of $2.2319 \%$ for men and $1.5127 \%$ for women. One other remark to be made here is that the notional rate awarded to men is generally higher than the interest rate for the same gender, while for women the situation is reversed. This is due to the use of the unisex mortality rates for determining the NDC pensions. The unisex mortality is higher than the female mortality and lower than the male one. Thus, in order to preserve the equality between the actuarially fair pension and the NDC pension for the two genders, men should receive a higher notional rate to compensate for the inferred longer lifespan, while women can be awarded a lower interest rate, since the unisex mortality rates are favourable for them. Similarly, the accrual rates for women are lower than for men, since unisex mortality is utilised to determine the 
contribution rate used to compute the theoretical pensions, this being coupled, of course, with the higher salaries earned by men. Moreover, we must note here that in the case of the DB scheme, the effects of salaries and entry ages in the system are mixed with the effects of the socio-economic mortality rates, since the contribution rates are based on the average individual and they affect only the theoretical pension. A different contribution rate for each class, based on their corresponding salaries and entry ages would allow us to separate the two effects. Such a solution, though not necessarily possible in practice, is discussed in Sect. 5.3.

Lastly, we can compare the obtained rates and the consequent pensions with the initial parameters and the pensions the individuals would have received (so in the case when $r=1.8 \%, A R=1 \%$ and $n r=1.8 \%$ ). We see that the accrual and notional rates for women in Table 3 are lower than the initial parameters. This is due to the fact that the systems were more generous for women (see Figs. 1b and $2 \mathrm{~b}$ ). Given that the DB and NDC pensions are increasing in the accrual and notional rates respectively, the lower rates for women mean that their pensions will decrease in order to meet the fair pensions. However, because the obtained rates are higher for lower classes, the pensions are not impacted to the same extend. For instance, decreasing the accrual rate from $1 \%$ to $0.8443 \%$ for class D1 induces a decrease in the DB pensions of $15.57 \%$, while for the class D5 passing to a rate of $0.9171 \%$ implies a difference of only $8.29 \%$. For the NDC pensions, the new notional rate for the women in class D1 results in a decrease of $12.5 \%$, while for the class D5 the corresponding percentage is $10.5 \%$. The situation is slightly different for men. Since men with higher education were advantaged by the DB scheme, while those in lower classes were loosing with respect to the fair pensions (see Fig. 1a), the accrual rates for the upper classes decrease with respect to the initial parameters, while for lower classes they increase. Hence men in class D1 receive an accrual rate of $0.907 \%$ instead of $1 \%$. At the other end, those in class D5 should get an accrual rate of $1.1872 \%$ instead of the initial $1 \%$. Thus the DB pension of those in class D1 will decrease by $9.3 \%$, while that of the individuals belonging to class D5 will increase by $18.7 \%$. In the NDC scheme, men of all classes are at a disadvantage when compared to the theoretical framework (see Fig. 2a). Hence men in class D1 receive a notional rate of $1.9033 \%$, while those in class D5 are awarded a notional rate of $2.2319 \%$, instead of the original $1.8 \%$. Hence the increase of the pension for men in class D1 is of only $3.17 \%$, while the increase for class D5 is of $17.8 \%$. As stated before, the rates given in Table 3, through their impact on the pensions, will close the gap between the fair pension and that actually received, in order to compensate for not using socio-economic mortality rates in the pension calculations, thus reducing the transfers from the lower classes to the higher ones.

\subsection{Extending the framework to include pension adequacy}

We consider pension adequacy in terms of a minimum pension $P_{\text {min }}$, which is defined as a percentage $R R_{\text {target }}$ of the mean salary in the system at time $t$, as given by Eq. (10) below. 


$$
P_{\text {min, } t}=R R_{\text {target }} \cdot \bar{W}_{t}
$$

As one of the goals of the social security system is to ensure a subsistence level for all individuals, it is only natural that such a target minimum pension is fixed within the system, at the legal retirement age. Depending on the chosen percentage $R R_{\text {target }}$, and thus on the level of the minimum pension, the interest rates, accrual rates and notional rates of those classes not reaching the intended target should be further adapted in order to allow these individuals to achieve the minimum required. To accomplish this, we look for the interest rates, accrual rates and notional rates that satisfy the equalities in Eq. (11). The adapted rates will thus depend on the chosen target level $P_{m i n, t}$ and implicitly on $R R_{\text {target }}$.

$$
P_{x_{r}^{i}, t}^{t h}\left(r^{i}\right)=P_{x_{r}^{i}, t}^{i, D B}\left(A R^{i}\right)=P_{x_{r}^{i}, t}^{i, N D C}\left(n r^{i}\right)=P_{m i n, t}
$$

In Switzerland, the subsistence level is defined as $40 \%$ of the mean salary in the system. Since the first pillar in France proposes a minimum pension of $37.5 \%$ of the average salary of the individual's career ${ }^{18}$, we decided, for illustration purposes, to keep the minimum standard to $40 \%$ of the average salary in the system ${ }^{19}$. We start by calculating the minimum pension at the legal retirement age $x_{\text {legal }}=65$, at time $t=2066$ and we display in Table 4 the pensions calculated using the parameters from Table 3, expressed in percentage of the target minimum pension, of course at age 65 .

We see that the pensions for women are lower than those of men, because of their lower income and higher longevity. Indeed, we see that at the legal retirement age of 65 , the pension for men with the highest level of education is more than $150 \%$ of the minimum, while women in the same class receive only $77 \%$ of the minimum pension. However, as expected, individuals with higher education benefit from higher pensions, and this regardless of the gender. If men in class D1 receive $169 \%$ of the minimum pension, those in class D4 only get $76 \%$ of the target pension. Similarly, women with an university degree reach $77 \%$ of the minimum pension, while the corresponding percentage for those in class D4 is $45 \%$.

Given the percentages displayed in Table 4, we will need to adjust the awarded rates for women belonging to all classes, as well as for men belonging to class D2, D4 and D5. The new rates yielded by Eq. (11) in this case are given in Table 5. We see, when comparing to the results in Table 3 , that the rates to be awarded to these groups have to be increased in order to allow them to reach the intended level of $40 \%$ for the average salary in the system. Thus, for example, women in class D1 should receive an interest rate of $2.4807 \%$ instead of $1.7585 \%$ and so the accrual rate would pass from $0.8443 \%$ to $1.0972 \%$, while the notional rate becomes $2.1646 \%$,

\footnotetext{
18 OECD [31] notes that the maximum accrual rate for the state pension of $50 \%$. The accrual rate is reduced by $1.25 \%$ for each missing quarter up to a maximum of 20 quarters. This translates into a minimum accrual rate of $37.5 \%(50 \%-1.25 \% \cdot 20 \cdot 50 \%)$.

19 This rate has also been indicated as the minimum subsistence level in Holzmann and Hinz [16], while Humblet and Silva [19] remark that a replacement rate of $45 \%$ is needed to ensure the minimum living standard.
} 
instead of $1.4198 \%$. Similarly, the interest, accrual and notional rate for the class D5 are now $3.3872 \%, 1.7189 \%$ and $3.1233 \%$, instead of $1.8214 \%, 0.9171 \%$ and $1.5127 \%$ respectively. The slightly lower rates awarded in this case to class D3, compared to the other classes, can be anticipated from the percentage of the minimum pension that they receive, since this class is the closest to the minimum level among the four groups given here, given the data on salaries used for the projections. Men in class D2 will receive an interest, accrual and notional rate of $1.8537 \%, 1.0898 \%$ and $2.1585 \%$ respectively after the adjustment, as opposed to the respective original $1.662 \%, 1.0206 \%$ and $1.9724 \%$. For the men in class D5 the rates pass from $1.9487 \%, 1.1872 \%$ and $2.2319 \%$ to $2.0547 \%, 1.2348 \%$ and $2.3351 \%$ for the interest rate, accrual rate and notional rate respectively. Of course, we remark once again that these results are meant to be just an illustration and thus, will depend on the minimum pension chosen and the data regarding the mortality and salaries for each class.

\section{Determining formally the class-specific rates}

In this section, we provide easy-to-implement formulas for adjusting the parameters of the pension schemes (as illustrated by the previous section), in order to compensate for the absence of mortality by socio-economic class in the benefit calculations. Our framework allows policy-makers to render the pension system fairer, in a simple way, and to fully quantify the importance of considering socio-economic heterogeneity in mortality through the observed differences in pensions that will arise after the parameters are adjusted.

\subsection{The general framework}

As mentioned in Sect. 3, class-specific mortality might not be used in the determination of the pensions. In fact, mortality rates by socio-economic class might not be available or complete enough to yield reliable projections. This should however not impede the process of adapting the parameters of the pensions schemes as described in Sect. 3 in order to improve the fairness of the system. In this sense, it is possible to express the class-specific rates mathematically, if the relationship between the mortality of the general population and the one of the class is known and this for each gender (either detailed data are available for one or a few years, or assumptions can be provided by expert opinions or by looking at the mortality experience of neighbouring countries). Hence, let us assume that the following relationship is known:

$$
p_{x, t}^{i}=p_{x, t} \cdot M_{x, t}^{i}
$$

In Eq. (12) $p_{x, t}^{i}$ is the probability of a person of age $x$ at time $t$, belonging to class $i$ to survive to age $x+1, p_{x, t}$ is the general survival probability of a person also aged $x$ at time $t$ (hence no class distinction considered) and $M_{x, t}^{i}$ is an age-specific, 
Table 4 Pensions per class determined using the rates in Table 3, in percentages of the minimum pension

\begin{tabular}{llllll}
\hline & D1 & D2 & D3 & D4 & D5 \\
\hline Men & 169 & 94 & 101 & 76 & 96 \\
Women & 77 & 53 & 60 & 45 & 53 \\
\hline
\end{tabular}

\begin{tabular}{|c|c|c|c|c|c|c|}
\hline \multirow[b]{2}{*}{ Class } & \multicolumn{3}{|l|}{ Male } & \multicolumn{3}{|l|}{ Female } \\
\hline & $r^{i}$ & $A R^{i}$ & $n r^{i}$ & $r^{i}$ & $A R^{i}$ & $n r^{i}$ \\
\hline D1 & - & - & - & 2.4807 & 1.0972 & 2.1646 \\
\hline D2 & 1.8537 & 1.0898 & 2.1585 & 3.4242 & 1.6218 & 3.1473 \\
\hline D3 & - & - & - & 3.1021 & 1.4394 & 2.8182 \\
\hline D4 & 2.5511 & 1.5006 & 2.8169 & 3.7824 & 2.0028 & 3.5262 \\
\hline D5 & 2.0547 & 1.2348 & 2.3351 & 3.3872 & 1.7189 & 3.1233 \\
\hline
\end{tabular}

Table 5 Class-specific parameters for individual retiring at age 65 in 2066, adjusted given $R R_{\text {target }}=40 \%$, in percentages

time-specific and class-specific factor defining the relationship between the class and the general population. We note here that the gender is not specified, to ease notation, as the mathematical expressions will be identical for both genders. Given Eq. (12), we can also express ${ }_{k} p_{x, t}^{i}$, the class-specific probability for a person aged $x$ at time $t$ to survive to age $x+k$, in function of ${ }_{k} p_{x, t}$ (the same probability, but without the class distinction) as below:

$$
{ }_{k} p_{x, t}^{i}={ }_{k} p_{x, t} \cdot \prod_{u=0}^{k-1} M_{x+u, t+u}^{i}
$$

In order to simplify the formulas, we drop the index $i$ from the entry and retirement age. Hence from here onwards we refer to the entry age as $x_{0}$ and to the retirement age as $x_{r}$. However, this does not change the generalisation aspect of this section. The formulas work the same, even if these ages would be class-specific.

As in Sect. 3.3, we would like to ensure the fairness of the system by allowing a different interest rate per class $r^{i}$ that would satisfy Eq. (7), in order to compensate for the use of the general mortality, instead of a class specific one. Consequently, we follow the process described in Sect. 3 by fixing the interest rate $r^{\text {fixed }}$ that should be used to calculate the class-specific theoretical pension $P_{x_{r}^{i}, t}^{i, t h}$ and solving Eq. (7) for the interest rate by class $r^{i}$. We can then show (the proof can be found in Section C) that Eq. (7) holds for: 


$$
\begin{aligned}
\frac{1}{1+r_{x, t-x_{r}+x}^{i}} & =\frac{M_{x, t-x_{r}+x}^{i}}{1+r^{\text {fixed }}} \\
r_{x, t-x_{r}+x}^{i} & =\frac{1+r^{\text {fixed }}}{M_{x, t-x_{r}+x}^{i}}-1
\end{aligned}
$$

From Eq. (14) above, we can deduce that, should the factor $M_{x, t-x_{r}+x}^{i}$ be larger than one, so in other words, should the survival probability of the class $i$ be larger than the general gender specific survival rate, then the interest rate to be awarded, $r_{x, t-x_{r}+x}^{i}$, will be smaller than $r^{\text {fixed }}$. Hence those with higher than average survival rates will receive lower interest rates. Conversely, should $M_{x, t-x_{r}+x}^{i}$ be smaller than one, the interest rate awarded will be larger than $r^{\text {fixed }}$. Ergo, those with lower survival probabilities will receive higher rates.

Using Eq. (8), we can easily express now the accrual rate for each class as a function of the theoretical pension as defined in Eq. (C.2.2), given the vector of interest rates $r_{v e c}^{i}=\left\{r_{x_{0}, t-x_{r}+x_{0}}^{i}, r_{x_{0}+1, t-x_{r}+x_{0}+1}^{i} \ldots, r_{\omega, t-x_{r}+\omega}^{i}\right\}$ found through Eq. 14:

$$
A R^{i}=\frac{P_{x_{r}, t}^{t h}\left(r_{v e c}^{i}\right)}{\bar{W}_{t}^{i} \cdot\left(x_{r}-x_{0}\right)}
$$

Lastly, we want to determine a formula for the notional rate of return for each class. For this, we first assume a similar relationship between the gender specific survival rate $p_{x, t}$ and the unisex rate $p_{x, t}^{\text {unisex }}$ as in Eq. (12), therefore we have:

$$
p_{x, t}=M_{x, t} \cdot p_{x, t}^{u n i s e x}
$$

Hence we find the following relationship between the interest rates and the notional rates (see Section D for details):

$$
\begin{aligned}
\frac{1}{1+r_{x, t-x_{r}+x}^{i}} & =\frac{1}{M_{x, t-x_{r}+x}\left(1+n r_{x, t-x_{r}+x}^{i}\right)} \\
\Longrightarrow n r_{x, t-x_{r}+x}^{i} & =\frac{1+r_{x, t-x_{r}+x}^{i}}{M_{x, t-x_{r}+x}}-1=\frac{1+r^{\text {fixed }}}{M_{x, t-x_{r}+x} \cdot M_{x, t-x_{r}+x}^{i}}-1
\end{aligned}
$$

Similarly to the case described in Eq. (14), should the factor $M_{x, t-x_{r}+x}$ be larger than one, so should the general gender-specific survival probability be larger than the corresponding unisex rate, then the notional rate awarded to class $i, n r_{x, t-x_{r}+x}^{i}$, will be smaller than the interest rate given to the same class $r_{x, t-x_{r}+x}^{i}$. Hence those that are favoured by the use of the unisex survival probabilities should receive lower notional rates. On the opposite side, should $M_{x, t-x_{r}+x}$ be lower than one, the notional rates will be larger than the respective interest rates. 


\subsection{A simplification}

In many situations, the relationship between the survival rates by age and time, governed by $M_{x, t-x_{r}+x}^{i}$ and $M_{x, t-x_{r}+x}$, might not be known in such details, so by age and time. However, it might be possible to estimate average factors that would be kept constant through time and across ages or make an assumption as simple as Eqs. (18) and (19), allowing pensions to still be adapted to increase fairness to all socio-economic classes.

$$
\begin{aligned}
& M_{x, t}^{i}=y^{i} \% \\
& M_{x, t}=z \%
\end{aligned}
$$

With these two factors constant, the interest rates will no longer be time and age dependent, but will remain class specific. We can thus simplify the above expressions for the class-specific rates, obtaining:

$$
r^{i}=\frac{1+r^{\text {fixed }}}{y^{i \%}}-1
$$

Consequently we obtain:

$$
\begin{gathered}
A R^{i}=\frac{P_{x_{r}, t}^{\text {th }}\left(r^{i}\right)}{\bar{W}_{t}^{i} \cdot\left(x_{r}-x_{0}\right)} \\
n r^{i}=\frac{\left(1+r^{i}\right)}{z \%}-1=\frac{\left(1+r^{f i x e d}\right)}{z \% \cdot y^{i \%}}-1
\end{gathered}
$$

To illustrate this, we estimate the two constant factors for the French data used in Sect. 3 by averaging across ages and across time. The values obtained are given in Table 6 . As expected, the values for $z \%$ are the same for every class, since this factor defines the ratio between the gender specific survival rate, when no class distinction is made, and the unisex survival rates. Moreover, this rate is higher for women, due to the fact that unisex mortality is higher than the female mortality. With regards to $y^{i} \%$, we note that the rate decreases with the class, with the higher classes having a survival rate superior than the general one. The differences appear smaller for women than for men, congruent with our observations from Sect. 3.

We then calculate the interest rates, accrual rates and notional rates according to Eqs. (20), (21) and (22) respectively. The results in this case are displayed in Table 7 . We see that though the rates are different than the ones in Table 3, the values are in general not far from the initial ones. For instance, the difference between the interest rates $r^{i}$ given in Table 3 and in Table 7 is of only $0.0384 \%$ for men in class D5, while the respective differences for the accrual and notional rate are, in this same case, $0.017 \%$ and $0.7353 \%$. Moreover, they allow us to draw the same conclusions as in Sect. 3.3. For women in the same class, the differences between 
the interest rates, accrual rates and notional rates from the two tables are $0.0778 \%$, $0.0288 \%$ and $0.5369 \%$ respectively. The lower classes require higher rates, with the spread between the newly obtained parameters being larger for men than for women. In conclusion, though not perfect, the approximation would allow providing fairer pensions, in function of the socio-economic class.

\section{Further analysis}

\subsection{No gender distinction}

In the European Union, differentiating between men and women is not legally allowed $^{20}$. Hence the solution proposed in Sect. 3.3, where the interest rates, accrual rates and notional rates were adjusted for each class and gender in order to improve the actuarial fairness of the schemes, might not be possible to apply. Hence, we perform a similar analysis as done above, when no gender differences are considered. Consequently, salaries and mortality are distinct for each socio-economic class, but do not take gender into account. In setting up the salaries for each class for our numerical illustration, while disregarding gender, we assume a ratio of $51-49 \%$ between women and men (in other words, the salaries for each class are composed of $51 \%$ of the salaries for women and $49 \%$ of those for men of the same class). Hence, the average salaries in the system are calculated, followed by the contribution rate and the bonus and penalty coefficients applied in the DB scheme. Consequently, the new contribution rate is $14.6 \%$. The accrual rate is set at $1 \%$, while the interest and notional rates are both $1.8 \%$, as done in Sect. 3.2.

We then proceed to calculating the differences in pension capitals for the DB and the NDC scheme, as given in Eq. (6). As in Sect. 3.2, the retirement ages considered are those from 50 to 75 , with the legal retirement age being 65 and the reference age $x_{\text {ref }}$ being set to 50. The results are displayed in Fig. 3. Firstly, we observe, as expected, that individuals with the highest level of education are the most advantaged by either one of the schemes, with their gain increasing with age. In the case of the DB scheme, we observe that the lower classes experience a loss with respect to the actuarially fair pension, though not significant. Moreover, higher retirement ages imply an even bigger loss. The situation is slightly reversed for those in class D2 and D3, who experience a gain that increases with age. Lastly, we note that the differences between classes D2 to D5 are not big, while those with the highest level of education receive a distinct advantage from the two schemes. The situation is similar for the NDC scheme, although the gain of class D1 is less significant. Moreover,

\footnotetext{
$\overline{20}$ Council Directive 79/7/EEC (see Directive [15]) specifically prohibits any discrimination between men and women in matters of social security. A famous court case in this respect is the one of Douglas Harvey Barber v Guardian Royal Exchange Assurance Group (see Shrubsall [40]), in which the European Court of Justice ruled that occupational pensions are subject to the principles of gender equality established in the Treaty of Rome. Moreover, in 2011 the European Court of Justice ruled that discrimination by gender is prohibited in the insurance sector. Hence pricing insurance contracts must be done without considering gender.
} 
Table 6 The factors governing the relationship between survival rates as given in Eqs. (18) and (19)

\begin{tabular}{llllll}
\hline & \multicolumn{2}{l}{ Male } & & \multicolumn{2}{c}{ Female } \\
\cline { 2 - 3 } \cline { 5 - 6 } Class & $y^{i}$ & & & $y^{i}$ & $z$ \\
\hline D1 & 100.54 & 99.82 & & 100.29 & 100.91 \\
D2 & 100.36 & 99.82 & & 100.24 & 100.91 \\
D3 & 100.21 & 99.82 & & 100.15 & 100.91 \\
D4 & 100.06 & 99.82 & & 100.12 & 100.91 \\
D5 & 99.82 & 99.82 & & 99.90 & 100.91 \\
\hline
\end{tabular}

Table 7 Class-specific parameters for individuals retiring at age 65 in 2066 , according to Eqs. (20), (21) and (22), in percentages

\begin{tabular}{|c|c|c|c|c|c|c|}
\hline \multirow[b]{2}{*}{ Class } & \multicolumn{3}{|l|}{ Male } & \multicolumn{3}{|l|}{ Female } \\
\hline & $r^{i}$ & $A R^{i}$ & $n r^{i}$ & $r^{i}$ & $A R^{i}$ & $n r^{i}$ \\
\hline D1 & 1.2502 & 0.8317 & 2.2232 & 1.5024 & 0.7696 & 0.5826 \\
\hline D2 & 1.4310 & 0.9432 & 2.4057 & 1.5582 & 0.7997 & 0.6379 \\
\hline D3 & 1.5876 & 1.0125 & 2.5638 & 1.6456 & 0.8272 & 0.7245 \\
\hline D4 & 1.7363 & 1.1053 & 2.7140 & 1.6789 & 0.8650 & 0.7574 \\
\hline D5 & 1.9871 & 1.2042 & 2.9672 & 1.8991 & 0.9459 & 0.9757 \\
\hline
\end{tabular}

those in class D2 and D3 see their gain increase when retirement is postponed, while those in class D4 will go from suffering a loss to experiencing a small gain the more retirement is pushed. However, those without any diploma will lose with respect to the theoretical framework and their disadvantage increases with the retirement age.

Subsequently, we applied the methodology described in Sect. 3.3 to adjust the parameters in order to allow the system to achieve actuarial fairness. As previously stated, we consider $r^{\text {fixed }}=1.8 \%$ and we set the retirement age to 65 . The results stemming from Eqs. (7), (8) and (9) in this case are given in Table 8. Of note here is that $P_{x_{r}, t}^{i, t h}\left(r^{\text {fixed }}\right)$ is calculated based on class-specific survival rate and class-specific salaries, without a gender distinction. It then follows that for $P_{x_{r}, t}^{t h}\left(r^{i}\right)$ we will use class-specific salaries, but unisex mortality rates. As expected, the observations to be made here are similar to those from Sect. 3.3. The awarded rates are lower for those in higher classes and higher for those in lower classes, to compensate for the not considering class-specific mortality rates in the calculation of the pensions. Hence those in class D1 will receive an interest rate of $1.6560 \%$, an accrual rate of $0.8889 \%$ and a notional rate of $1.6560 \%$, while for those in class D5 the interest, accrual and notional rates are $1.8848 \%, 1.0704 \%$ and $1.8848 \%$ respectively. Moreover, we note that the interest rates $r^{i}$ and the notional rates $n r^{i}$ have the same values, since, when no gender distinction is made, the two pensions are equivalent. Lastly, we can compare the newly obtained rates with our initial parameters $(r=1.8 \%$, $A R=1 \%$ and $n r=1.8 \%$ ). As expected, we see that only those in class D5 will receive an interest rate and a notional rate above the initial value of $1.8 \%$, but that the adjusted rates are close to the initial parameters, indicating that only this class was facing a loss with respect to the theoretical pension, in 2066. The accrual rates for classes D1 to D3 are slightly lower than the initial $1 \%$, since the individuals 


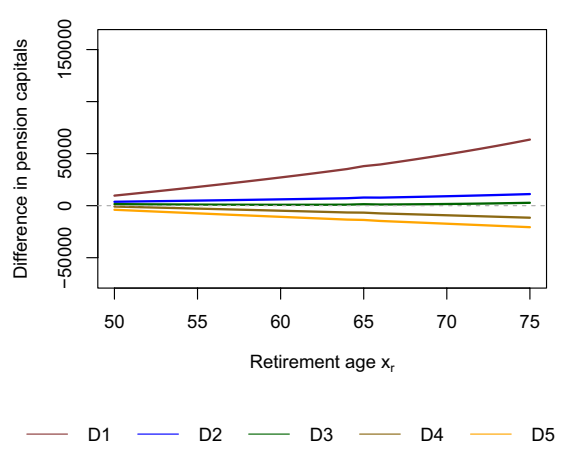

(a) $P V_{x_{r e f}, t}^{i, D B}\left(x_{r}\right)$

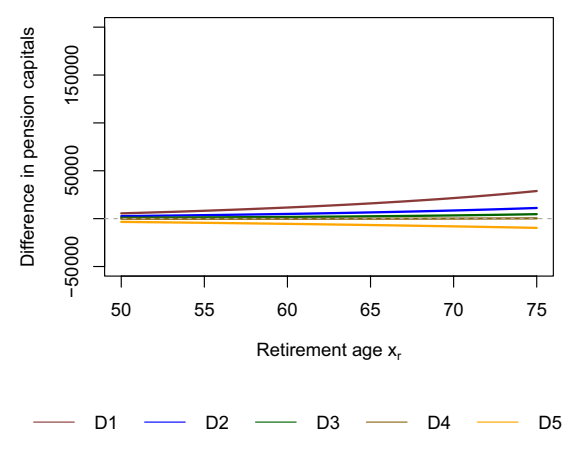

(b) $P V_{x_{r e f}, t}^{i, N D C}\left(x_{r}\right)$

Fig. 3 Difference between the DB or NDC pension capital and the theoretical pension capital, for individuals entering the system in 2016, when no gender differences are considered

Table 8 Class-specific parameters for individuals retiring at age 65 in 2066 , when no gender distinction is considered, in percentages

\begin{tabular}{llll}
\hline Class & $r^{i}$ & $A R^{i}$ & $n r^{i}$ \\
\hline D1 & 1.6560 & 0.8898 & 1.6560 \\
D2 & 1.7146 & 0.9620 & 1.7146 \\
D3 & 1.7692 & 0.9922 & 1.7692 \\
D4 & 1.7996 & 1.0395 & 1.7996 \\
D5 & 1.8848 & 1.0704 & 1.8848 \\
\hline
\end{tabular}

belonging to these classes were favoured by the DB scheme, while those in the remaining classes are awarded rates above $1 \%$ to compensate for their losses with respect to the actuarially fair pension.

As in Sect. 3.4, we are also interested in making sure that the pensions reach adequacy. In other words, individuals should receive at least the minimum pension, defined in our numerical example as $40 \%$ of the average salary in the system. Given the rates presented in Table 8 , we start by computing the corresponding pensions as percentages of the minimum pension and we display the results in Table 9. In this case, when no gender distinction is applied, only those in class D1 reach the intended pension target. The remaining classes are below the threshold for pension adequacy, with class D2 reaching only $75 \%$ of the minimum pension and class D4 obtaining $62 \%$ of the same reference amount. Lastly, we note that the lower pensions for classes D2 to D5 are also due to the fact that the salaries in this case are based on a slightly higher proportion of female wages than male.

Given the results displayed in Table 8, the interest, accrual and notional rates for classes D2 to D5 should be adjusted to ensure that the pensions are adequate. In other words, we repeat the process explained in Sect. 3.4 and given by Eq. 11. The corresponding rates can be found in Table 10. The individuals belonging to class D2 should thus receive an interest, accrual and notional rate of $2.5255 \%, 1.2875 \%$ and $2.5260 \%$ 
Table 9 Pensions per class determined using the rates in Table 8, in percentages of the minimum pension

\begin{tabular}{llllll}
\hline & D1 & D2 & D3 & D4 & D5 \\
\hline Unisex & 121 & 75 & 82 & 62 & 76 \\
\hline
\end{tabular}

respectively. For class D4 the corresponding values are $3.0567 \%, 1.6900 \%$ and $3.0572 \%$. As explained, the new rates will allow the pensions for these classes to reach the minimum target pension. These results are in line with our previous observations, given in Sect. 3.

\subsection{Adjusting the parameters at retirement}

In the analysis provided until now, we have considered socio-economic differences from the beginning of the working career. However, this might be difficult to implement in practice. Thus, a possible alternative that would be easier to put in practice for the policy makers consists of considering the differences in mortality based on socioeconomic class only for the retirement phase. This section analyses this option in more depth. In other words, for the following analysis, all individuals are considered equal with respect to their mortality during the active life and the class-specific rates should only be applied from the retirement age onward.

Though the definition of the DB and NDC pensions does not change, our methodology for determining the class-specific rates needs to be reviewed. Moreover, in this section we add to the analysis the case of no gender distinction, as to keep in mind the limitations described in Sect. 5.1 above.

Let us begin with how the notional rate in a NDC scheme can be adjusted at the retirement age. As previously explained, in such a scheme the individuals accumulate a notional capital, which is then transformed into an annuity using unisex mortality rates. Since we are interested in considering socio-economic differences in mortality starting from the retirement time, we must differentiate between the active phase and the retirement phase for each socio-economic class. During the active phase, all classes will receive the same notional rate, while the notional rate awarded at retirement will be distinct for each class and will allow us to compensate for the use of unisex mortality rates instead of class-specific mortality rates. Hence the NDC pension at the legal retirement age $x_{\text {legal }}$ can be rewritten as in Eq. (23), with $n r^{a c t}$ the notional rate awarded during the active life to all individuals, regardless of class. For simplification purposes, the formula assumes the notional rate during the active phase is constant for the duration. However, the methodology presented here can take into account a notional rate changing yearly. Our numerical illustration will account for both possibilities.

$$
P_{x_{\text {legal }}, t}^{i, N D C}\left(n r^{i}\right)=\frac{\pi \cdot \sum_{x=x_{0}^{i}}^{x_{\text {legal }}-1} L_{x, t-x_{\text {legal }}+x}^{\text {unisex }} \cdot W_{x, t-x_{\text {legal }}+x}^{i} \cdot\left(1+n r^{a c t}\right)^{x_{\text {legal }}-x}}{\ddot{a}_{x_{\text {legal }}, t}^{\text {unisex }, \beta}\left(n r^{i}\right) \cdot L_{x_{\text {legal }}, t}^{\text {unisex }}}
$$


Table 10 Class-specific parameters for individuals retiring at age 65 in 2066, adjusted given $R R_{\text {target }}=40 \%$, when no gender distinction is made, in percentages

\begin{tabular}{llll}
\hline Class & $r^{i}$ & $A R^{i}$ & $n r^{i}$ \\
\hline D2 & 2.5255 & 1.2875 & 2.5260 \\
D3 & 2.3076 & 1.2083 & 2.3081 \\
D4 & 3.0567 & 1.6900 & 3.0572 \\
D5 & 2.6127 & 1.4166 & 2.6132 \\
\hline
\end{tabular}

$$
=\frac{A c c \operatorname{Cap}^{i}}{\ddot{a}_{x_{\text {legal }}, t}^{\text {unisex }, \beta}\left(n r^{i}\right)}
$$

We also redefine the theoretical pension at the legal retirement age $x_{\text {legal }}$ as given in Eq. (25), where $A c c C a p^{i}$ is the capital accumulated under the NDC scheme by an individual belonging to class $i$ and $r_{\text {ret }}$ is the interest rate at the moment of retirement (the rate for which the equation $(1+r)=(1+d) \cdot(1+g)$ holds, at the time of the retirement). Since the mortality differences are considered only at retirement, it is only logical that the accumulated capital should be the same for the NDC and the theoretical pension.

$$
P_{x_{\text {legal }}, t}^{i, t h}\left(r_{\text {ret }}\right)=\frac{\operatorname{AccCap}{ }^{i}}{\ddot{a}_{x_{\text {legal }}, t, t}^{i, \beta}\left(r_{\text {ret }}\right)}
$$

Subsequently, we look for the notional rate $n r^{i}$ that solves Eq. (26). As already explained, our goal is to determine the class-specific notional rates $n r^{i}$ that will allow us to compensate for not using the mortality rates by socio-economic class in the calculation of the NDC pension.

$$
P_{x_{\text {legal }}, t}^{i, t h}\left(r_{r e t}\right)-P_{x_{\text {legal }}, t}^{i, N D C}\left(n r^{i}\right)=0
$$

If we develop Eq. (26) as done in Sect. 4, using Eqs. (12) and (16), we obtain a the same formula as given in Eq. (17), with $x \geq x_{\text {legal }}$ and $r_{\text {ret }}$ taking the place of $r^{\text {fixed }}$.

To illustrate this part of our paper, we start by assuming a constant notional rate of $1.8 \%$ for the active life, as well as an interest rate at retirement of $1.8 \%$. This corresponds to the parameters used in Sect. 3. Hence the contribution rate stays at the level of $14.3 \%$. The legal retirement age is considered 65, while the indexation stays zero. The solutions of Eq. (26) are given in Table 11. Because the accumulated capital is the same for the NDC and the theoretical pension, the contribution rate impacts both pensions in the same way and thus has no effect on the results stemming from Eq. (26). We observe that the notional rates for men of all classes are higher than $1.8 \%$, while the rates awarded to women are lower than the interest rate at retirement. This is in line with our previous analysis and the values displayed in Fig. 2 and is due to the use of unisex mortality rates for the NDC pension. Moreover, we see once more that the rates for lower classes are higher than those for higher classes, allowing us to compensate for the use of unisex mortality rates in the calculation of the NDC pension. Hence men in class D1 are awarded a rate of $2.0415 \%$, 
while those in class D5 receive $2.7528 \%$ starting at the retirement age. For women in class D1 the notional rate in this case is $0.96 \%$, while for those with no education the corresponding value is $1.1059 \%$. When no gender distinction is made, the notional rates are lower than the interest rate at retirement for all classes, except for class D5. Those with the highest level of education receive a notional rate of $1.5214 \%$, while the individuals with no education are awarded a rate of $1.9550 \%$. As for men and women, the rates for the higher classes are below those for the lower classes. The results are once again in line with the values displayed in Fig. 3b. To further our analysis, we also take into account that at retirement, the interest rate might suffer a shock, even if the notional rate during the active period is $1.8 \%$. If the interest rate at retirement is $1.5 \%$ and not $1.8 \%$, the values for the class-specific notional rates are recalculated and are given in Table 11, alongside the results discussed above. The conclusions in this case are the same as those for the previous case, when the interest rate at retirement is $1.8 \%$. We note that men receive higher rates than women, with the value of the interest rate at retirement of $1.5 \%$ being lower than the notional rates for men and higher than the notional rates for women. This is once more due to the use of unisex mortality rates in the calculation of the NDC pension. Moreover, individuals in higher class receive lower notional rates than those in lower classes. Hence the notional rates for class D1 are $1.7459 \%$ for men and $0.6502 \%$ for women. For those in class D5, the notional rates are $2.4598 \%$ and $0.7982 \%$ for men and women respectively. A similar conclusion can be drawn when no gender distinction is made, with the notional rate for class D1 being $1.2191 \%$ and the corresponding value for class D5 reaching a level of $1.6551 \%$.

As an additional step, we allow the notional rate during the active life to differ each year. In order to accomplish this, we fix the growth rate of salaries to $1.4 \%$ and we fit an $\operatorname{ARIMA}(1,1,2)$ model $^{21}$ to the historical growth rate of the French population. Subsequently, we project the values of $d_{t}$ by simulating 100 paths for the growth rate of population ${ }^{22}$. We then determine the notional rate for each year using the relationship $1+n r_{t}^{a c t}=(1+g) \cdot\left(1+d_{t}\right)$. At the retirement age, the interest rate $r_{r e t}$ corresponds to the notional rate of that specific year. Given the different simulations, the notional rates for each class and gender, as well as those with no gender distinction are determined according to Eq. (26). Figures 4, 5 and 6 show the simulations for the notional rates during the active phase in black, as well as the results for the class-specific rates for men, women and when no gender distinction is made respectively, for two chosen simulations. The interest rate at retirement is $2.34 \%$ in the first depicted simulation and $2.71 \%$ in the second. Our previous observations hold in this case as well. We observe that men will receive a notional rate higher than the interest rate (in black in the plots), with men with the lowest level of education having a higher notional rate than the rest. For women, the notional rates are lower than the interest rate at retirement, but once again women with the lowest education receive the highest notional rates. Moreover, as before, we observe that the

\footnotetext{
21 The model chosen presents the lowest AIC value.

22 Only paths with positive values are considered as simulations, since it is the most reasonable assumption.
} 
Table 11 Class-specific notional rates for individuals retiring at age 65 in 2066, when class distinctions in mortality are considered from retirement, in percentages

\begin{tabular}{|c|c|c|c|c|c|c|}
\hline \multirow[b]{2}{*}{ Class } & \multicolumn{3}{|c|}{$r_{r e t}=1.8$} & \multicolumn{3}{|c|}{$r_{r e t}=1.5$} \\
\hline & $n r^{i}$ men & $n r^{i}$ women & $n r^{i}$ unisex & $n r^{i}$ men & $n r^{i}$ women & $n r^{i}$ unisex \\
\hline D1 & 2.0415 & 0.9600 & 1.5214 & 1.7459 & 0.6502 & 1.2191 \\
\hline D2 & 2.2042 & 0.9766 & 1.6139 & 1.9096 & 0.6671 & 1.3123 \\
\hline D3 & 2.3835 & 1.0096 & 1.7206 & 2.0894 & 0.7006 & 1.4195 \\
\hline D4 & 2.4912 & 1.0232 & 1.7838 & 2.1978 & 0.7143 & 1.4831 \\
\hline D5 & 2.7528 & 1.1059 & 1.9550 & 2.4598 & 0.7982 & 1.6551 \\
\hline
\end{tabular}

differences are more significant for men than for women. When no distinction for gender is made, only those in class D5 will receive a rate higher than the interest rate at retirement, with the remaining classes situated below the level. This is expected, since the values for salaries and class-specific mortality in this case are based on a gender distribution of $51 \%$ for women and $49 \%$ for men.

We are now interested in adjusting the accrual rate at the retirement age in a DB scheme. As expected, since there is no capital accumulation in this type of scheme, a similar reasoning as that described for the NDC scheme and given in Eqs. (25) and (26) does not apply. We describe the process of adjusting the accrual rate at retirement in the remainder of this section. As previously explained, for an accrual rate fixed by the system, to which we will refer here as $A R_{s y s}$, the contribution rate is calculated, based on the salary and mortality of the average individual. Hence the system assumes that the present value of benefits to be paid depends on the unisex mortality rates. However, in reality, the class-specific mortality rates will drive the present value at retirement of the benefits. Hence we are looking for the accrual rate for each class that will allow the two present values specified above to be equal. This is given in Eq. (27), with $P_{x_{\text {legal }}^{i, t}, t, D B}^{\text {to }}\left(A R_{s y s}\right) \cdot \ddot{a}_{x_{\text {legal }}, t}^{\text {unisex }, \beta}$ the amount that the system assumes the individual will receive and $A R_{\text {ret }}^{i}$ the accrual rate that will allow the present value of what is actually paid to the individual to equate the value presumed by the system.

$$
P_{x_{\text {legal }}, t}^{i, D B}\left(A R_{s y s}\right) \cdot \ddot{a}_{x_{\text {legal }}, t}^{\text {unisex }, \beta}-P_{x_{\text {legal }}, t}^{i, D B}\left(A R_{r e t}^{i}\right) \cdot \ddot{a}_{x_{\text {legal }}, t}^{i, \beta}=0
$$

Developing Eq. (27), we obtain the accrual rate for each class as given in Eq. (28).

$$
A R_{\text {ret }}^{i}=A R_{\text {sys }} \cdot \frac{\ddot{a}_{x_{\text {legal }}, t}^{\text {unise }, \beta}}{\ddot{a}_{x_{\text {legal }}, t}^{i, \beta}}
$$

In our numerical illustration, we keep the accrual rate set by the system to $1 \%$ (hence $A R_{\text {sys }}=1 \%$ ) and the indexation rate to 0 . The interest rate used to calculate the values of the annuities is kept at $1.8 \%$. The resulting accrual rates for each class are given in Table 12, for men, women and when no gender distinction is made. The observations to be made here are in line with our previous analysis on the notional 


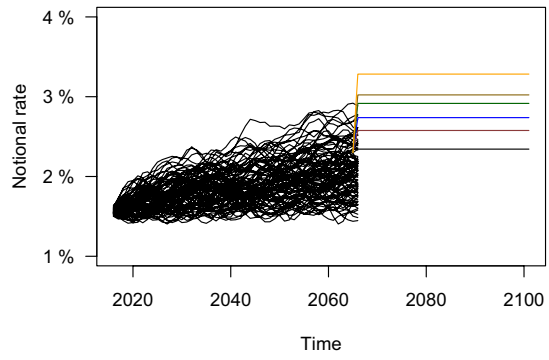

D1

(a) Simulation 1

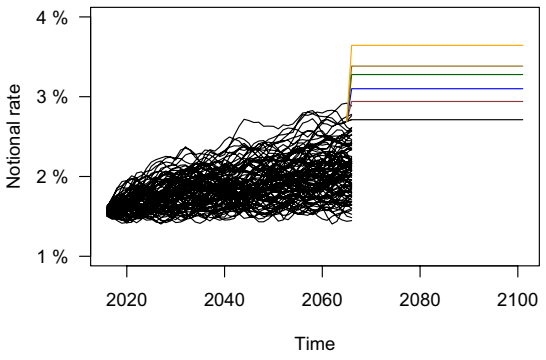

D1

(b) Simulation 2

Fig. 4 Class-specific notional rates for men retiring in 2066, based on simulations of the rates during the active phase

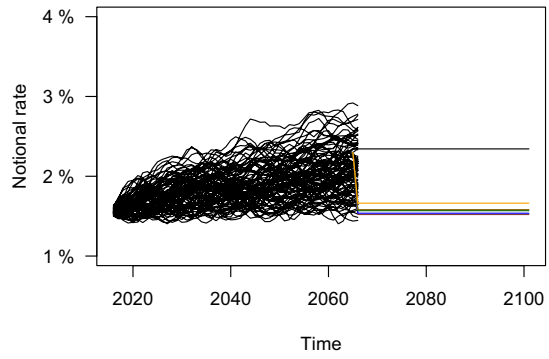

$\longrightarrow \mathrm{D} 1-\mathrm{D} 2-\mathrm{D} 3-\mathrm{D} 4-\mathrm{D} 5$

(a) Simulation 1

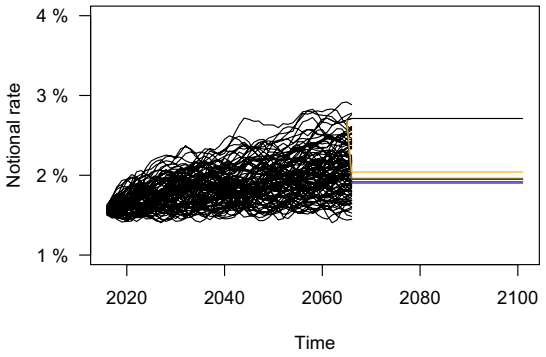

D2

D5

(b) Simulation 2

Fig. 5 Class-specific notional rates for women retiring in 2066, based on simulations of the rates during the active phase

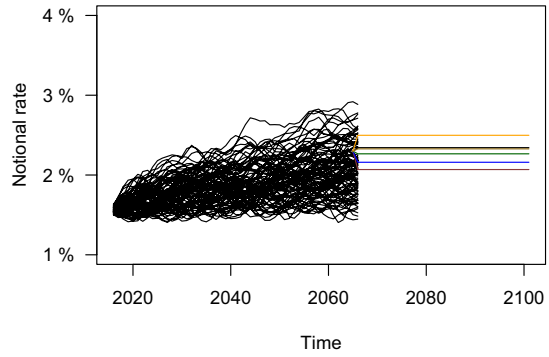

$\longrightarrow \mathrm{D} 1-\mathrm{D} 2-\mathrm{D} 3-\mathrm{D} 4 \longrightarrow \mathrm{D} 5$

(a) Simulation 1

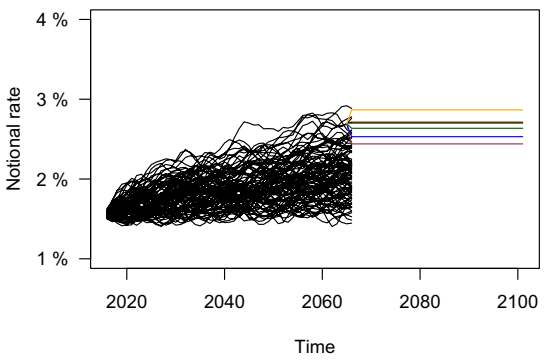

$-\mathrm{D} 1-\mathrm{D} 2-\mathrm{D} 3-\mathrm{D} 4-$

(b) Simulation 2

Fig. 6 Class-specific notional rates for individuals retiring in 2066, when no gender distinction is made, based on simulations of the rates during the active phase 
Table 12 Class-specific accrual rates for individuals retiring at age 65 in 2066, when class distinctions in mortality are considered from retirement, in percentages

\begin{tabular}{llll}
\hline Class & $A R_{\text {ret }}^{i}$ men & $A R_{\text {ret }}^{i}$ women & $A R_{\text {ret }}^{i}$ unisex \\
\hline D1 & 1.0314 & 0.8942 & 0.9643 \\
D2 & 1.0528 & 0.8962 & 0.9761 \\
D3 & 1.0766 & 0.9003 & 0.9898 \\
D4 & 1.0910 & 0.9019 & 0.9979 \\
D5 & 1.1263 & 0.9122 & 1.0201 \\
\hline
\end{tabular}

rates. When the mortality differentials are only accounted for starting at retirement, men will receive higher rates than the fixed $1 \%$, while the accrual rate for women is lower. For the case when no gender distinction is made, only those with no education receive a rate higher than $1 \%$. However, the main conclusion still stands. Individuals in lower classes are awarded higher accrual rates than those in higher classes. Therefore, men in class D1 receive an accrual rate of $1.0314 \%$, while those in class D5 are awarded a rate of $1.1263 \%$. The corresponding rates for women are $0.8942 \%$ for class D1 and $0.9122 \%$ for class D5. When no gender distinction is made, the accrual rate for those with the higher education is $0.9643 \%$, while for those with no education the rate awarded is $1.0201 \%$. Lastly, we note here that a change in the interest rate used for calculating the annuities will not lead to significant changes in the results, since the rate impacts both annuities.

Furthermore, we must remark here on the principal disadvantage of such an approach, namely considering the socio-economic differences only once the individuals reach retirement. Although this option might be easier to implement from the point of view of the policy makers, it will still slightly disadvantage those in lower socio-economic classes, as it does not account for their higher mortality during the active life. Hence the notional rates and accrual rate will not completely compensate for the lower life expectancy of those belonging to lower socio-economic classes. For instance, in the NDC scheme, since the accumulation phase does not consider the higher mortality for those groups, the survival dividends taken into account are lower than they should be. Moreover, for the DB scheme the accrual rate for those of lower classes are lower than the ones provided in Table 3, suggesting an insufficient compensation for the socio-economic differences. Still comparing between the two tables, we observe that the differences between the accrual rates given to each class are smaller when the socio-economic distinctions are only considered at retirement. This holds for both genders. Similarly, for the NDC scheme, as the active phase is identical between all the individuals, the differences between the classes are smaller in this case than when socio-economic differences are taken into account for the entire duration of the working life.

\subsection{Different contribution rates}

As previously explained, the choice of the contribution rates do not impact the values of the notional rates to be awarded, since both the NDC and the theoretical pension are affected by the contribution rates in the same way. However, the DB pension 
does not depend on the contribution rate, while the theoretical pension is impacted by it, hence a different contribution rate will lead to different accrual rates than those displayed in Tables 3 and 10. Since the contribution rate of $14.3 \%$ is fixed based on unisex mortality, average salaries and an entry age in the system of 17, the effects of the class-specific mortality on the accrual rates of Tables 3 and 10 are mixed with the effects of the class-specific salaries and entry ages. To remedy this situation and isolate the effect of the mortality by socio-economic class, the evolution of salaries for each class and gender, as well as the corresponding entry ages should be considered in the calculation of the contribution rates. The resulting values, using classspecific salaries and entry ages, but unisex mortality rates, are given in Table 13. As expected, the contribution rates for higher classes are higher, indifferent of gender, since they enter the system later and since their earning are higher. Moreover, women should pay a lower contribution rate than men to reflect their lower salaries.

Given the contribution rates given in Table 13, we recalculate the accrual rates to be awarded to each class. The corresponding values are given in Table 14. We observe that the accrual rates for those in lower classes are higher than for those with the highest level of education. Hence men in class D5 should receive an accrual rate of $1.1778 \%$, while women in the same class should be awarded a rate of $0.8952 \%$ and when no gender distinction is considered the accrual rate is $1.0329 \%$ for the same class. For class D1 the accrual rates are $1.0191 \%, 0.8734 \%$ and $0.9472 \%$ for men, women and when no gender distinction is made, respectively. However, in this case the differences between classes are reduced in the case of men and the values overall are approaching those in Table 12. Moreover, we see that the rates for men are higher than the fixed accrual rate of $1 \%$, while those for women are lower than the same fixed rate. When no gender distinction is made, only those with no education receive an accrual rate higher than $1 \%$. As expected the differences between the classes are smaller in this case, when compared to the results in Table 3, since the distinction in contribution rates accounts for a part of the socio-economic gap. However, we note that setting the contribution rates differently for each socio-economic class to reflect the corresponding differences in salaries and entry ages does not completely explain and eliminate the discrepancies between the classes. This points towards the significant impact of the socio-economic mortality rates. Hence compensating for the lack of use of class-specific mortality rates remains an important task, in order to improve the fairness of the system and lower the disadvantage for the lower socio-economic classes.

We summarise the different scenarios considered in this paper in Table 15, along with the key findings for each case.

\section{Conclusions}

In this paper, we focus on the actuarial fairness of the Defined Benefit and the Notional Defined Contribution pension scheme, when mortality rates differ by socio-economic class. We show, through a numerical example based on data by level of education from the French Office of Statistics, that these schemes can indeed be unfair. This is due to the fact that neither the DB, nor the NDC scheme incorporates 
Table 13 Class-specific contribution rates

\begin{tabular}{llll}
\hline Class & $\pi^{i}$ men & $\pi^{i}$ women & $\pi^{i}$ unisex \\
\hline D1 & $16.07 \%$ & $14.78 \%$ & $15.53 \%$ \\
D2 & $14.84 \%$ & $14.48 \%$ & $14.68 \%$ \\
D3 & $14.58 \%$ & $14.47 \%$ & $14.53 \%$ \\
D4 & $14.09 \%$ & $13.97 \%$ & $14.04 \%$ \\
D5 & $14.19 \%$ & $13.95 \%$ & $14.09 \%$ \\
\hline
\end{tabular}

\begin{tabular}{llll}
\hline Class & $A R^{i}$ men & $A R^{i}$ women & $A R^{i}$ unisex \\
\hline D1 & 1.0191 & 0.8734 & 0.9472 \\
D2 & 1.0593 & 0.8761 & 0.9682 \\
D3 & 1.0966 & 0.8809 & 0.9879 \\
D4 & 1.1196 & 0.8826 & 0.9999 \\
D5 & 1.1778 & 0.8952 & 1.0329 \\
\hline
\end{tabular}

Table 14 Accrual rates for individuals retiring at age 65 in 2066, when contribution rates are different for each class, in percentages

mortality rates by socio-economic class. We find that not only do the DB and NDC pensions differ from the actuarially fair pension, but they also tend to advantage those with higher education. In reverse, individuals belonging to lower classes lose with respect to the actuarially fair pensions. We can thus conclude that socio-economic differences in mortality have a significant impact on the fairness of the retirement systems, be they the DB or NDC type. Therefore, mortality by socio-economic class should be included in the pension calculations. However, this is rarely done in practice. One reason for this could be the scarcity of data. Another possible explanation lies in the additional complexity introduced when considering the socio-economic mortality rates, since a new variable is added to the systems. An alternative is therefore required in order to help improve the fairness of the systems. Hence, we propose a simple methodology that allows each system to adapt its parameters, namely the interest rates, the accrual rates and the notional rates of return, for each socio-economic class. Our numerical example allows us to see that the rates should be higher for lower socio-economic groups, while individuals with higher education would receive lower rates. Subsequently, we looked beyond the fairness of each system and included pension adequacy in our framework. Hence, in order to allow all individuals to attain a given minimum pension level, the parameters for each system would need to be adapted again, for those not reaching the target value. In our example, we fix the minimum desired pension to $40 \%$ of the average salary in the system at the moment of retirement. Therefore, the class-specific rates need to be increased only for those not reaching the intended level.

We also provide simple mathematical formulas that allow us to determine the rates for each class, both when data on socio-economic level is enough to determine the relationship between class-specific survival rates and general survival probabilities, and when no data is available, but a simple hypothesis about the ratio between these two types of survival rates can be made. Our framework thus serves 


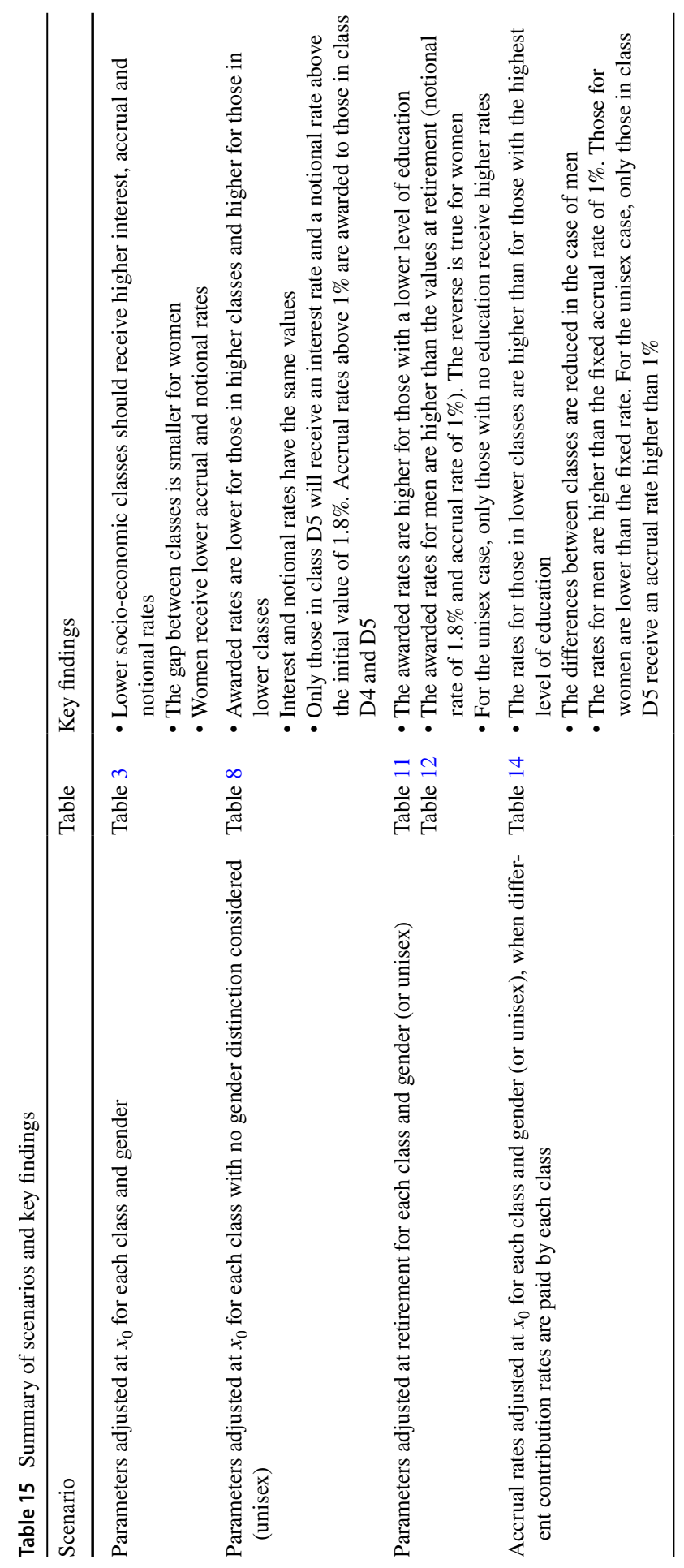


a double purpose. Firstly, it provides an easily-implementable tool to policy-makers that would help improve the actuarial fairness of the pension systems. Furthermore, our simplified version allows us to reduce the additional complexity listed above, since, in this version of our model, the mortality rates for each class are linked to the general gender-specific rates through a single parameter, constant throughout age and time. Although using the simplification means that the actuarial fairness is not perfectly met, it is still a step in the right direction. Secondly, our framework can be used simply to fully understand and quantify the impact of mortality by socioeconomic class, since the pensions would be different by socio-economic class. Our numerical illustration already suggests that the above-mentioned impact is non-negligible and so this could be the case for all the countries around the world.

Lastly, we provide further analysis regarding the parameters to be adapted for reaching higher actuarial fairness. We offer a numerical illustration for the case when no gender distinction is made, as well as when contribution rates can be different for each class for the DB system. Our conclusions are in line with the previous analysis. Individuals in higher classes should be awarded lower rates, while those in lower classes should receive higher parameters, to compensate for not considering class-specific mortality rates in the calculations of the pensions. All the above mentioned situations are viewed from the moment of entry in the system. In other words, the parameters are adjusted for the duration of the career. However, this might be difficult to promote and implement. Hence a more accessible solution for policy makers would be to allow the parameters to be adapted at retirement, so the mortality differentials with respect to the socio-economic class are only considered starting from the retirement age. This point of view is also illustrated in our paper. The conclusions remain the same. However, it must be said that this method still disadvantages those in lower socio-economic classes, since it does not account for their higher mortality rates even before retirement. One alternative for fixing this issue would be to adjust the parameters each year, thus implementing a dynamic framework. This represents an avenue of further research stemming from the present study.

Another avenue to be explored that is closely linked to our methodology here would be how could the retirement age be adapted for each class, instead of the parameters considered here, to account for socio-economic mortality differences. Intuitively, individuals of lower socio-economic classes would retire earlier than those belonging to higher classes, since their life expectancy is lower.

The point of solidarity in a social security system is to redistribute wealth from the richer individuals to those in poorer conditions. However, as our example clearly illustrates, by not taking into account socio-economic differences in mortality the opposite might happen. Hence transfers from those in lower socio-economic classes to those in higher classes might take place, thus contradicting the aim of a social security system. In conclusion, our methodology comes as a solution to this situation, allowing fairer pensions and hence reducing the transfers from the poor to the rich. Therefore, our framework can and should be used to close the gap between the fair pensions and those actually awarded by the pension systems, and this for each socio-economic class, in order to compensate for the fact that the pension systems do not account for differences in mortality by socio-economic class. 


\section{Appendix A: The salaries}

In order to project the salaries for each class, we assume homogeneity across active members of the same age. Thus, the wages for a person of age $x$ at time $t \geq 2012$ are given by the Eq. (29), where $t_{0}=2012$ :

$$
W_{x, t}^{i}=W_{x, t_{0}}^{i} \cdot\left(1+g_{x}^{i}\right)^{t-t_{0}}
$$

We use the historical data for the period from 2006 to $2012^{23}$ to calculate the annual growth rate of wages for age $x$ and class $i, g_{x}^{i}$, as per Eq. (30) below:

$$
\begin{gathered}
g_{x}^{i}=\left(\prod_{j=0}^{5}\left(1+g_{x, j}^{i}\right)\right)^{1 / 6}-1 \\
g_{x, j}^{i}=\frac{S_{x, 2006+j+1}^{i}-S_{x, 2006+j}^{i}}{S_{x, 2006+j}^{i}} \quad 0 \leq j \leq 5
\end{gathered}
$$

In Eq. (31), $g_{x, j}^{i}$ is the growth rate of salaries from one period to the next one for each class $i$ and $S_{x, 2006+j}^{i}$ is the annual salary for a person of age $x$ and class $i$ at time $2006+j$. The obtained values for the growth rate of wages $g_{x}^{i}$ for men and women are presented in Table 16.

\section{Appendix B: Mortality}

The historical mortality rates per level of education go from ages 30 to 100 for the years 1991-2013, grouped per periods. Hence we have three sets of mortality rates, namely for the periods 1991-1999, 2000-2008 and 2009-2013. Given the historical data for the period 2009-2013, we find that life expectancy at age 65 for men belonging to class D1 is 20.01 years, while for those in class D5 the value is 16.65 years. At the same age, women with the highest education (D1) are expected to live another 23.01 years, while those with no diploma have a life expectancy of only 20.6 years. Hence we see not only a significant difference between genders, with women living longer than men, but also between classes. It thus becomes important to include class differences in mortality in the calculations of pensions, alongside those of gender.

Since we do not have the raw mortality rates or the disaggregated data per year for the number of deaths and the exposure to risk, a time trend cannot be extrapolated. We hence use the extension of the Lee-Carter model proposed by $\mathrm{Li}$ and Lee [23], also referred to as the common factor model, to project the mortality rates per each group $i$ and gender, approximating the force of mortality $\mu_{x, t}^{i}$ by the central

\footnotetext{
23 The historical data used comes from the website of INSEE: https://www.insee.fr/fr/statistiques/23827 40 ? sommaire $=2130417$, and is available with the authors upon demand.
} 
death rate $m_{x, t}^{i}$. The common factor model is given by Eq. (32) below, where $\alpha_{x}^{i}$ represents the class-specific and age-specific average mortality behaviour.

$$
\log m_{x, t}^{i}=\alpha_{x}^{i}+\beta_{x}^{p} \kappa_{t}^{p} .
$$

In the bilinear term $\beta_{x}^{p} \kappa_{t}^{p}, \beta_{x}^{p}$ corresponds to the age specific difference in mortality with respect to the average mortality for the entire population (hence the index $p$ ), while $\kappa_{t}^{p}$ represents the evolution of the entire population's mortality across time. Hence the product is the same for all groups and derived by applying the modified Lee-Carted model proposed by Brouhns et al. [11] to the French population directly. In the model described by Brouhns et al. [11], the death count for each age and time is Poisson distributed and the mortality would be derived from Eq. (33).

$$
\log m_{x, t}^{p}=\alpha_{x}^{p}+\beta_{x}^{p} \kappa_{t}^{p} .
$$

We also impose the two usual constraints:

$$
\begin{aligned}
& \sum_{x} \beta_{x}^{p}=1 \\
& \sum_{t} \kappa_{t}^{p}=0 .
\end{aligned}
$$

Going back to Eq. (32), we follow the framework of Li and Lee [23] and estimate the term $\alpha_{x}^{i}$ by applying an OLS regression, which leads to the expression given in Eq. (36), with $T+1$ the number of periods available:

$$
\alpha_{x}^{i}=\frac{\sum_{t=0}^{T} \log \hat{m}_{x, t}^{i}}{T+1} .
$$

Since we only have the values of $q_{x, t}^{i}$ (the mortality rate for a person of age $x$ at time $t$ and of class $i$ ), we determine $\hat{m}_{x, t}^{i}$ by following Pitacco et al. [36] as given in Eq. (37) below.

$$
\hat{m}_{x, t}^{i}=\frac{\hat{q}_{x, t}^{i}}{1-0.5 \cdot \hat{q}_{x, t}^{i}} .
$$

Therefore, we start by estimating the Lee Carter parameters for the female and male French population, using log likelihoods, fitted to the data from the Human Mortality Database for the period 1816-2015. We then use an ARIMA model to project $\kappa_{t}^{p}$ for each gender ${ }^{24}$ for a horizon of 100 years, in order to further determine the mortality rates for the ages $15-100$.

\footnotetext{
${ }^{24}$ We use an $\operatorname{ARIMA}(1,1,1)$ for men and an $\operatorname{ARIMA}(2,2,3)$ for women, which correspond to minimum values of AIC.
} 
Table 16 Growth rate of wages for men and women, in percentages

\begin{tabular}{lllllll}
\hline Gender & Growth rate & D1 & D2 & D3 & D4 & D5 \\
\hline Men & $g_{15-29}^{i}$ & 2.26 & 1.29 & 1.91 & 1.76 & 2.25 \\
& $g_{30-49}^{i}$ & 0.62 & 1.24 & 1.83 & 0.77 & 1.98 \\
& $g_{50+}^{i}$ & 2.47 & 1.15 & 1.54 & 0.32 & 1.26 \\
\multirow{4}{*}{ Women } & $g_{15-29}^{i}$ & 1.95 & 1.47 & 2.19 & 0.59 & 2.47 \\
& $g_{30-49}^{i}$ & 1.17 & 0.90 & 1.67 & 1.11 & 2.11 \\
& $g_{50+}^{i}$ & 0.86 & 0.74 & 1.50 & 0.27 & 1.25 \\
\hline
\end{tabular}

By using Eq. (32), we then project mortality rates for each group from D1 to D5. For ages below 30, since we do not have class-specific mortality data, we assume that $\alpha_{x}^{i}=\alpha_{x}^{p} \cdot \frac{\alpha_{30}^{i}}{\alpha_{30}^{p}}$, for $x<30$.

\section{Appendix C: Interest rates by socio-economic class}

As explained in Sect. 4.1, we want to determine the interest rates per socio-economic class that would compensate for not using the class-specific mortality rates in the pension benefit calculations, thus allowing us to achieve greater actuarial fairness. In order to simplify the formulas, we drop the index $i$ from the entry and retirement age. Hence from here onwards we refer to the entry age as $x_{0}$ and to the retirement age as $x_{r}$.

We start by rewriting Eq. (5) using Eqs. (13) and (4), as well as the fixed interest rate $r^{\text {fixed: }}$

$$
\begin{aligned}
& P_{x_{r}, t}^{i, t h} \\
& =\frac{\pi \cdot \sum_{x=x_{0}}^{x_{r}-1} W_{x, t-x_{r}+x}^{i} \cdot\left(1+r^{\text {fixed }}\right)^{-\left(x-x_{0}\right)} \cdot{ }_{x-x_{0}} p_{x_{0}, t-x_{r}+x_{0}}^{i}}{\ddot{a}_{x_{r}, t}^{i, \beta}\left(r^{f i x e d}\right) \cdot{ }_{x_{r}-x_{0}} p_{x_{0}, t-x_{r}+x_{0}}^{i} \cdot\left(1+r^{f i x e d}\right)^{-\left(x_{r}-x_{0}\right)}} \\
& =\frac{\pi \cdot \sum_{x=x_{0}}^{x_{r}-1} W_{x, t-x_{r}+x}^{i} \cdot\left(1+r^{f i x e d}\right)^{-\left(x-x_{0}\right)} \cdot{ }_{x-x_{0}} p_{x_{0}, t-x_{r}+x_{0}} \cdot \prod_{u=0}^{x-x_{0}-1} M_{x_{0}+u, t-x_{r}+x_{0}+u}^{i}}{\left(\sum_{k=0}^{\omega-x_{r}}\left(\frac{1+\beta}{1+r^{f i x e d}}\right)^{k} \cdot{ }_{k} p_{x_{r}, t} \cdot \prod_{u=0}^{k-1} M_{x_{r}+u, t+u}^{i}\right)}
\end{aligned}
$$

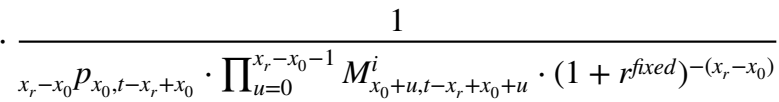

$$
\begin{aligned}
& =\frac{\pi \cdot \sum_{x=x_{0}}^{x_{r}-1} W_{x, t-x_{r}+x}^{i} \cdot{ }_{x-x_{0}} p_{x_{0}, t-x_{r}+x_{0}} \cdot \prod_{u=0}^{x-x_{0}-1} \frac{M_{x_{0}+u, t-x_{r}+x_{0}+u}^{i}}{1+r \text { fixed }}}{\left(\sum_{k=0}^{\omega-x_{r}}(1+\beta)^{k} \cdot{ }_{k} p_{x_{r}, t} \cdot \prod_{u=0}^{k-1} \frac{M_{x_{r}+u, t+u}^{i}}{1+r^{f i x e d}}\right) \cdot{ }_{x_{r}-x_{0}} p_{x_{0}, t-x_{r}+x_{0}} \cdot \prod_{u=0}^{x_{r}-x_{0}-1} \frac{M_{x_{0}+u, t-x_{r}+x_{0}+u}^{i}}{1+r \text { fixed }}}
\end{aligned}
$$


On the other hand, the theoretical pension when no class difference is considered for mortality rates, namely $P_{x_{r}, t}^{t h}$, is given by Eq. (39).

$$
P_{x_{r}, t}^{t h}\left(r^{i}\right)=\frac{\pi \cdot \sum_{x=x_{0}}^{x_{r}-1} W_{x, t-x_{r}+x}^{i} \cdot{ }_{x-x_{0}} p_{x_{0}, t-x_{r}+x_{0}} \cdot\left(1+r^{i}\right)^{-\left(x-x_{0}\right)}}{\left(\sum_{k=0}^{\omega-x_{r}}(1+\beta)^{k} \cdot{ }_{k} p_{x_{r}, t}\left(1+r^{i}\right)^{-k}\right) \cdot{ }_{x_{r}-x_{0}} p_{x_{0}, t-x_{r}+x_{0}} \cdot\left(1+r^{i}\right)^{-\left(x_{r}-x_{0}\right)}}
$$

We can now rewrite Eq. (7) as follows:

$$
\begin{aligned}
& \frac{\pi \cdot \sum_{x=x_{0}}^{x_{r}-1} W_{x, t-x_{r}+x}^{i} \cdot{ }_{x-x_{0}} p_{x_{0}, t-x_{r}+x_{0}} \cdot\left(1+r^{i}\right)^{-\left(x-x_{0}\right)}}{\left(\sum_{k=0}^{\omega-x_{r}}(1+\beta)^{k} \cdot{ }_{k} p_{x_{r}, t}\left(1+r^{i}\right)^{-k}\right) \cdot{ }_{x_{r}-x_{0}} p_{x_{0}, t-x_{r}+x_{0}} \cdot\left(1+r^{i}\right)^{-\left(x_{r}-x_{0}\right)}} \\
& -\frac{\pi \cdot \sum_{x=x_{0}}^{x_{r}-1} W_{x, t-x_{r}+x}^{i} \cdot{ }_{x-x_{0}} p_{x_{0}, t-x_{r}+x_{0}} \cdot \prod_{u=0}^{x-x_{0}-1} \frac{M_{x_{0}+u, t-x_{r}+x_{0}+u}^{i}}{1+r^{f x x e d}}}{\left(\sum_{k=0}^{\omega-x_{r}}(1+\beta)^{k} \cdot{ }_{k} p_{x_{r}, t} \cdot \prod_{u=0}^{k-1} \frac{M_{x_{r}+u, t+u}^{i}}{1+r^{\prime x x e d}}\right) \cdot{ }_{x_{r}-x_{0}} p_{x_{0}, t-x_{r}+x_{0}} \cdot \prod_{u=0}^{x_{r}-x_{0}-1} \frac{M_{x_{0}+u, t-x_{r}+x_{0}+u}^{i}}{1+r^{\prime x x e d}}}=0
\end{aligned}
$$

In order for Eq. (40) to hold, we require that the interest rate used to calculate Eq. (39) varies across age and time, in addition to the already considered socio-economic class. Hence, Eq. (39) becomes Eq. (41) below, with $r_{x, t}^{i}$ the interest rate dependent on the age $x$, time $t$ and class $i$ and $r_{v e c}^{i}=\left\{r_{x_{0}, t-x_{r}+x_{0}}^{i}, r_{x_{0}+1, t-x_{r}+x_{0}+1}^{i} \ldots, r_{\omega, t-x_{r}+\omega}^{i}\right\}$.

$$
P_{x_{r}, t}^{\text {th }}\left(r_{\text {vec }}^{i}\right)=\frac{\pi \cdot \sum_{x=x_{0}}^{x_{r}-1} W_{x, t-x_{r}+x}^{i} \cdot{ }_{x-x_{0}} p_{x_{0}, t-x_{r}+x_{0}} \cdot \prod_{u=0}^{x-x_{0}-1} \frac{1}{1+r_{x_{0}+u, t-x_{r}+x_{0}+u}^{i}}}{\left(\sum_{k=0}^{\omega-x_{r}}(1+\beta)^{k} \cdot{ }_{k} p_{x_{r}, t} \prod_{u=0}^{k-1} \frac{1}{1+r_{x_{r}+u, t+u}^{i}}\right) \cdot{ }_{x_{r}-x_{0}} p_{x_{0}, t-x_{r}+x_{0}} \cdot \prod_{u=0}^{x_{r}-x_{0}-1} \frac{1}{1+r_{x_{0}+u, t-x_{r}+x_{0}+u}^{i}}}
$$

Once again, we can plug Eq. (41) in Eq. (7), resulting in:

$$
\begin{gathered}
\frac{\pi \cdot \sum_{x=x_{0}}^{x_{r}-1} W_{x, t-x_{r}+x}^{i} \cdot{ }_{x-x_{0}} p_{x_{0}, t-x_{r}+x_{0}} \cdot \prod_{u=0}^{x-x_{0}-1} \frac{1}{1+r_{x_{0}+u, t-x_{r}+x_{0}+u}^{i}}}{\left(\sum_{k=0}^{\omega-x_{r}}(1+\beta)^{k} \cdot{ }_{k} p_{x_{r}, t} \prod_{u=0}^{k-1} \frac{1}{1+r_{x_{r}+u, t+u}^{i}}\right) \cdot{ }_{x_{r}-x_{0}} p_{x_{0}, t-x_{r}+x_{0}} \cdot \prod_{u=0}^{x_{r}-x_{0}-1} \frac{1}{1+r_{x_{0}+u, t-x_{r}+x_{0}+u}^{i}}} \\
-\frac{\pi \cdot \sum_{x=x_{0}}^{x_{r}-1} W_{x, t-x_{r}+x}^{i} \cdot{ }_{x-x_{0}} p_{x_{0}, t-x_{r}+x_{0}} \cdot \prod_{u=0}^{x-x_{0}-1} \frac{M_{x_{0}+u, t-x_{r}+x_{0}+u}^{i}}{1+r^{f x e d}}}{\left(\sum_{k=0}^{\omega-x_{r}}(1+\beta)^{k} \cdot{ }_{k} p_{x_{r}, t} \prod_{u=0}^{k-1} \frac{M_{x_{r}+u, t+u}^{i}}{1+r \text { fixed }}\right) \cdot{ }_{x_{r}-x_{0}} p_{x_{0}, t-x_{r}+x_{0}} \cdot \prod_{u=0}^{x_{r}-x_{0}-1} \frac{M_{x_{0}+u, t-x_{r}+x_{0}+u}^{i}}{1+r^{f \text { xued }}}}
\end{gathered}
$$

The below relationship, corresponding to Eq. (14), is needed between the interest rates for each $x \in\left[x_{0}, \omega\right]$ and given that the age $x_{r}$ is reached at time $t$, to ensure that Eq. (42) holds: 


$$
\begin{aligned}
\frac{1}{1+r_{x, t-x_{r}+x}^{i}} & =\frac{M_{x, t-x_{r}+x}^{i}}{1+r^{\text {fixed }}} \\
r_{x, t-x_{r}+x}^{i} & =\frac{1+r^{\text {fixed }}}{M_{x, t-x_{r}+x}^{i}}-1
\end{aligned}
$$

\section{Appendix D: Notional rates by socio-economic class}

After determining the interest rates for each socio-economic class (see Section C), we would like to determine the class-specific notional rates that would ensure the equality in Eq. (9), with the purpose, as before, of reaching greater actuarial fairness.

We can firstly rewrite Eq. (3) as follows:

$$
P_{x_{r}, t}^{i, N D C}=\frac{\pi \cdot \sum_{x=x_{0}}^{x_{r}-1} W_{x, t-x_{r}+x}^{i} \cdot{ }_{x-x_{0}} p_{x_{0}, t-x_{r}+x_{0}} \cdot \prod_{u=0}^{x-x_{0}-1} \frac{1}{M_{x_{0}+u, t-x_{r}+x_{0}+u} \cdot\left(1+n r^{i}\right)}}{\left(\sum_{k=0}^{\omega-x_{r}}(1+\beta)^{k} \cdot{ }_{k} p_{x_{r}, t} \prod_{u=0}^{k-1} \frac{1}{M_{x_{r}+u, t+u} \cdot\left(1+n r^{i}\right)}\right) \cdot \frac{x_{r}-x_{0} p_{x_{0}, t-x_{r}+x_{0}}}{\prod_{u=0}^{x_{r}-x_{0}-1} M_{x_{0}+u, t-x_{r}+x_{0}+u} \cdot\left(1+n r^{i}\right)}}
$$

According to Eq. (9), we should determine the notional rate that ensures the equality between Eqs. (43) and (41). Thus the notional rate has to evolve across age and time, as well as class, similarly to the interest rate. We rewrite Eq. (43) as follows, with $n r_{x, t}^{i}$ the notional rate for class $i$, at age $x$ reached at time $t$ :

$$
P_{x_{r}, t}^{i, N D C}=\frac{\left.\pi \cdot \sum_{x=x_{0}}^{x_{r}-1} W_{x, t-x_{r}+x}^{i} \cdot{ }_{x-x_{0}} p_{x_{0}, t-x_{r}+x_{0}} \cdot \prod_{u=0}^{x-x_{0}-1} \frac{1}{M_{x_{0}+u, t-x_{r}+x_{0}+u} \cdot\left(1+n r_{x_{0}+u, t-x_{r}+x_{0}+u}^{i}\right.}\right)}{\left(\sum_{k=0}^{\omega-x_{r}} \frac{(1+\beta)^{k}{ }_{k} p_{x_{r}, t}}{\prod_{u=0}^{k-1} M_{x_{r}+u, t+u} \cdot\left(1+n r_{x_{r}+u, t+u}^{i}\right)}\right) \cdot \frac{x_{r}-x_{0} p_{x_{0}, t-x_{r}+x_{0}}}{\prod_{u=0}^{x_{r}-x_{0}-1} M_{x_{0}+u, t-x_{r}+x_{0}+u} \cdot\left(1+n r_{x_{0}+u, t-x_{r}+x_{0}+u}^{i}\right)}}
$$

By inserting Eqs. (41) and (44) into Eq. (9), we find the following relationship between the interest rates and the notional rates, corresponding to Eq. (17):

$$
\begin{aligned}
\frac{1}{1+r_{x, t-x_{r}+x}^{i}} & =\frac{1}{M_{x, t-x_{r}+x}\left(1+n r_{x, t-x_{r}+x}^{i}\right)} \\
\Longrightarrow n r_{x, t-x_{r}+x}^{i} & =\frac{1+r_{x, t-x_{r}+x}^{i}-1=\frac{1+r^{\text {fixed }}}{M_{x, t-x_{r}+x}}-1=1}{M_{x, t-x_{r}+x} \cdot M_{x, t-x_{r}+x}^{i}}-1
\end{aligned}
$$

Funding Open Access funding provided by Université de Lausanne.

Open Access This article is licensed under a Creative Commons Attribution 4.0 International License, which permits use, sharing, adaptation, distribution and reproduction in any medium or format, as long as you give appropriate credit to the original author(s) and the source, provide a link to the Creative Commons licence, and indicate if changes were made. The images or other third party material in this article are included in the article's Creative Commons licence, unless indicated otherwise in a credit line to the 
material. If material is not included in the article's Creative Commons licence and your intended use is not permitted by statutory regulation or exceeds the permitted use, you will need to obtain permission directly from the copyright holder. To view a copy of this licence, visit http://creativecommons.org/licen ses/by/4.0/.

\section{References}

1. Alonso-García J, Devolder P (2019) Continuous time model for notional defined contribution pension schemes: liquidity and solvency. Insurance Math Econ 88:57-76

2. Arnold S, Boado-Penas MC, Godínez-Olivares H (2016) Longevity risk in notional defined contribution pension schemes: a solution. Geneva Pap Risk Insurance-Issues Pract 41(1):24-52

3. Ayuso M, Bravo JM, Holzmann R (2017) On the heterogeneity in longevity among socioeconomic groups: scope, trends, and implications for earnings-related pension schemes. Glob J Hum Soc SciEcon 17(1):33-58

4. Barnay T (2007) Redistributive impact of differential mortality in the french pay-as-you-go system. Geneva Pap Risk Insurance-Issues Pract 32(4):570-582

5. Belloni M, Maccheroni C (2013) Actuarial fairness when longevity increases: an evaluation of the Italian pension system. Geneva Pap Risk Insurance-Issues Pract 38(4):638-674

6. Bisetti E, Favero C (2014) Measuring the impact of longevity risk on pension systems: the case of Italy. North Am Actuar J 18(1):87-103

7. Bodie Z, Marcus A, Merton R (1988) Defined benefit versus defined contribution pension plans: what are the real trade-offs? In: Pensions in the US Economy, pp 139-162. University of Chicago Press

8. Börsch-Supan A (2006) What are NDC Systems? What do they bring to Reform Strategies? Pension reform, issues and prospects for non-financial defined contribution (NDC) schemes, pp 35-55

9. Bowers N, Gerber H, Hickman J, Jones D, Nesbitt C (1997) Actuarial mathematics, (Schaumburg, IL: Society of Actuaries)

10. Bravo J, Ayuso M, Holzmann R (2017) Addressing longevity heterogeneity in pension scheme design and reform. J Finance Econ 6:1-21

11. Brouhns N, Denuit M, Vermunt J (2002) A poisson log-bilinear regression approach to the construction of projected lifetables. Insurance Math Econom 31(3):373-393

12. Brown J (2003) Redistribution and insurance: mandatory annuitization with mortality heterogeneity. J Risk Insurance 70(1):17-41

13. Caselli G, Peracchi F, Barbi E, Lipsi RM (2003) Differential mortality and the design of the Italian system of public pensions. Labour 17:45-78

14. Chetty R, Stepner M, Abraham S, Lin S, Scuderi B, Turner N, Bergeron A, Cutler D (2016) The association between income and life expectancy in the united states, 2001-2014. JAMA 315(16):1750-1766

15. Directive Council (1979) 79/7/eec of 19 december 1978 on the progressive implementation of the principle of equal treatment for men and women in matters of social security. OJL 6:10.01

16. Holzmann R, Hinz R (2005) Old-age income support in the 21st century: an international perspective on pension systems and reform. The World Bank

17. Holzmann R, Alonso-García J, Hardy H-L, Villegas A (2019) NDC Schemes and Heterogeneity in Longevity: proposals for Redesign. In: Progress and challenges of nonfinancial defined pension schemes-Volume 1: adressing marginalization, polarization and the labour market, chapter 16, pages xx-xxx. The World Bank

18. Hörner W, Döbert H, Reuter L, Kopp B (2007) The education systems of Europe, vol 7. Springer, Berlin

19. Humblet M, Silva R (2002) Standards for the xxist century: social security. ILO

20. Kisser M, Kiff J, Oppers S, Soto M (2012) The impact of longevity improvements on US corporate defined benefit pension plans

21. Kudrna G, Tran C, Woodland A et al (2018) Sustainable and equitable pensions with means testing in aging economies. In: ARC Centre of Excellence in Population Ageing Research Working Paper 2018/21

22. Kuivalainen S, Nivalainen S, Järnefelt N, Kuitto K (2018) Length of working life and pension income: empirical evidence on gender and socioeconomic differences from Finland. J Pension Econ Finance 2018:1-21 
23. Li N, Lee R (2005) Coherent mortality forecasts for a group of populations: an extension of the Lee-Carter method. Demography 42(3):575-594

24. Määttänen N, Võrk A, Piirits M, Gal R, Jarocinska E, Ruzik A, Nijman T (2014) The impact of living and working longer on pension income in five European Countries: Estonia, Finland, Hungary, the Netherlands and Poland. In: Case report no. 476/2014

25. Mazzaferro C, Morciano M, Savegnago M (2012) Differential mortality and redistribution in the Italian notional defined contribution system. J Pension Econ Finance 11(4):500-530

26. Meara E, Richards S, Cutler D (2008) The gap gets bigger: changes in mortality and life expectancy, by education, 1981-2000. Health Aff 27(2):350-360

27. Munnell A, Webb A, Chen A (2016) Does socioeconomic status lead people to retire too soon? Age 60(62):65

28. Nelissen J (1999) Mortality differences related to socioeconomic status and the progressivity of old-age pensions and health insurance: the Netherlands. Eur J Popul 15(1):77-97

29. OCDE (2019) Pensions at a Glance 2019. https://doi.org/10.1787/b6d3dcfc-en. https://www. oecd-ilibrary.org/content/publication/b6d3dcfc-en

30. OECD (2014) Mortality assumptions and longevity risk. https://doi.org/10.1787/9789264222748en. https://www.oecd-ilibrary.org/content/publication/9789264222748-en

31. OECD (2015) Pensions at a Glance 2015. https://doi.org/10.1787/pension_glance-2015-en. https://www.oecd-ilibrary.org/content/publication/pension_glance-2015-en

32. OECD (2017) Pensions at a Glance 2017. https://doi.org/10.1787/pension_glance-2017-en. https://www.oecd-ilibrary.org/content/publication/pension_glance-2017-en

33. Oeppen J, Vaupel J (2002) Broken limits to life expectancy. Science 296(5570): 1029-1031 (ISSN 0036-8075). https://doi.org/10.1126/science.1069675. URL http://science.sciencemag. org/content/296/5570/1029

34. Olshansky J, Antonucci T, Berkman L, Binstock R, Boersch-Supan A, Cacioppo J, Carnes B, Carstensen L, Fried L, Goldman D et al (2012) Differences in life expectancy due to race and educational differences are widening, and many may not catch up. Health Aff 31(8):1803-1813

35. Palmer E (2006) What's ndc? In: Robert H, Edward EP et al (eds) Pension reform: issues and prospects for non-financial defined contribution (NDC) schemes, chapter 2, pp 17-35. World Bank Publications

36. Pitacco E, Denuit M, Haberman S, Olivieri A (2009) Modelling longevity dynamics for pensions and annuity business. Oxford University Press, Oxford

37. Rutledge M, Sanzenbacher G, Sass S, Wettstein G, Crawford C, Gillis C, Belbase A, Munnell A, Webb A, Chen A et al (2018) What explains the widening gap in retirement ages by education? In: Center for retirement research issue brief, pp 10-18

38. Sanzenbacher G, Webb A, Cosgrove C, Orlova N (2015) Calculating neutral increases in retirement age by socioeconomic status. In: CRR working papers, center for retirement research at boston college

39. Shkolnikov V, Scholz R, Jdanov D, Stegmann M, Von Gaudecker H-M (2007) Length of life and the pensions of five million retired German men. Eur J Pub Health 18(3):264-269

40. Shrubsall V, Barber V (1990) Guardian royal exchange assurance group [1990] irlr 240;[1990] 2 all er 660 (ecj). Industr Law J 19(4):244-250

41. Stenberg A, Westerlund O (2013) Education and retirement: does University education at mid-age extend working life? IZA J Eur Labor Stud 2(1):16

42. Stevens R (2017) Managing longevity risk by implementing sustainable full retirement age policies. J Risk Insurance 84(4):1203-1230

43. Van Berkum F, Antonio K, Vellekoop M (2020) Quantifying longevity gaps using micro-level lifetime data. J R Stat Soc A Stat Soc 00:1-23

44. Venti S, Wise D (2015) The long reach of education: early retirement. J Econ Ageing 6:133-148

45. Vidal-Meliá C, del Carmen Boado-Penas M, Navarro-Cabo F (2015) Notional defined contribution pension schemes: why does only Sweden distribute the survivor dividend? J Econ Pol Reform 2015:1-21

46. Villegas A, Haberman S (2014) On the modeling and forecasting of socioeconomic mortality differentials: an application to deprivation and mortality in England. North Am Actuar J 18(1):168-193

47. Wilcox D (2006) Reforming the defined-benefit pension system. Brook Pap Econ Act 2006(1):235-304

48. World Bank (1994) Averting the old age crisis: Policies to protect the old and promote growth. Washington DC; World Bank. URL http://documents.worldbank.org/curated/en/973571468174557 899/Averting-the-old-age-crisis-policies-to-protect-the-old-and-promote-growth 
49. World Bank (2005) Notional accounts: Notional defined contribution plans as a pension reform strategy. World Bank Pension Reform Primer Series

Publisher's Note Springer Nature remains neutral with regard to jurisdictional claims in published maps and institutional affiliations. 